\title{
Emigrantes a la isla Española en 1506
}

Juan Gil

Universidad de Sevilla

Se reúne y sistematiza en este artículo toda la documentación referente a la emigración española a Santo Domingo en 1506.

Palabras Clave: Emigración, Mujeres, Hernán Cortés, Ovando, Santo Domingo, barcos a las Indias.

In this paper are collected and organised all the documents relating to the spanish emigration to Santo Domingo in 1506.

KeYwords: Emigration, women, Hernán Cortés, Ovando, Santo Domingo, ships to the Indies.

Los protocolos notariales de Sevilla, al igual que suplen de algún modo la falta del segundo Libro de Armadas a Indias, así también colman otra sensible laguna documental: la pérdida de los libros de pasajeros que hubieron de llevar los oficiales de la Casa de la Contratación en los primeros años del siglo XVI. Los documentos escribaniles permiten fijar con alguna aproximación, por desgracia nunca suficiente, el número y la procedencia de los hombres que se embarcaron hacia un mundo nuevo'.

Los legajos que interesan a nuestro propósito son trece, aunque el oficio IV, el de Manuel Segura, fuera el preferido por los viajeros transatlánticos para otorgar sus últimas escrituras antes de partir. Es lástima que la fecha de las escrituras redactadas en el registro de Segura sea incierta con más frecuencia de la deseable, por lo que se ha optado, en caso de duda, no dar la data, indicando sólo en el índice anexo la secuencia cronológica general.

Tras el gran esfuerzo poblacional hecho en 1502, a lo largo del trienio 1503-1505 no se registraron grandes movimientos migratorios, a pesar de las plagas y las hambrunas que asolaron a la Península Ibérica, o quizás por ellas. En cambio, el año 1506, no menos mortífero (al igual que 1507)2, arroja un porcentaje realmente extraordinario de pasajeros a Indias. Es muy

1 El presente artículo es continuación del publicado en Historiografía y Bibliografía americanista. Sigo utilizando, pues, las mismas siglas y abreviaturas que usé en aquel trabajo. 
posible que esta emigración masiva, procedente de un país diezmado por la peste, tuviera a su vez efectos deletéreos en la demografía indígena, al someter a los habitantes de la Española a una nueva y devastadora infección. La sugerencia de este posible contagio, propuesta por N. D. Cook en un libro muy interesante ${ }^{3}$, cobra, a la luz de los documentos que estudio, mayores visos de verosimilitud. Sea como fuere, la muy real amenaza de que se propagaran al Nuevo Mundo los miasmas de Sevilla alarmó, y con razón, al gobernador Ovando, a quien tuvo que confortar Fernando el Católico, quizá con demasiado optimismo, el 21 de octubre de 1507:

Lo del temor que allá teníades de los navíos que ivan de partes donde morían de pestilencia ya cesará, pues, a Dios gracias, en los dichos lugares ha cesado la pestilencia. A Él plega de guardar lo de allá y lo de acá4.

Escribano

Juan Ruiz de Porras
Manuel Segura (enero-abril)
(mayo-julio)
(agosto-setiembre)
(octubre-noviembre)
(noviembre-diciembre)
Juan Álvarez de Alcalá
Aguilar
Francisco Ruiz de Porras
Diego Álvarez Chico
Bernal González de Vallecillo

Oficio

$\begin{array}{llll}\text { III 1506 }(1503) & = & 3.1506 \\ \text { IV 1506, } 1(2169) & = & 4.1506,1 \\ \text { IV 1506, } 2(2170) & = & 4.1506,2 \\ \text { IV 1506, 3 }(2171) & = & 4.1506,3 \\ \text { IV 1506, 4 }(2172) & = & 4.1506,4 \\ \text { IV 1506, 5 }(2173) & = & 4.1506,5 \\ \text { V 1506, 3 }(3226) & = & 5.1506,3 \\ \text { VII 1506 (4887) } & = & 7.1506 \\ \text { X 1506 }(5826) & = & 10.1506 \\ \text { XI 1506 (6678) } & = & 11.1506 \\ \text { XV 1506, 1 (9103) } & = & 15.1506,1 \\ \text { XV 1506, 2(9104) } & = & 15.1506,2 \\ \text { XXI 1506 (14227) } & = & 21.1506\end{array}$

Las escrituras nos enseñan a distinguir entre los hombres que fueron a sueldo y los que emigraron por su cuenta y riesgo. Empecemos por pasar revista a los asalariados y a sus patrones. Es de notar que entre los primeros se observa un aumento considerable del número de casados. Ése era

2 La mortandad se revela en el gran número de testamentos otorgados en 1506 y 1507, que supera con creces la media normal en los años anteriores y posteriores.

3 La conquista biológica. Las enfermedades en el Nuevo Mundo, Siglo XXI, 2005, pág. 61.

4 AGI, Indiferente General, 1961, I, 4v (CDIU V, pág. 119). 
uno de los objetivos de la política de la Corona, sin duda; pero también a los amos les interesaba tener a su servicio a personas más hechas y formales en teoría y que, con un hogar ya establecido, no pondrían reparo alguno a la hora de regresar a la Península una vez que se cumpliese el plazo fijado en el contrato. El mismo criterio se aplicó a los esclavos 5 .

No figura en esta larga lista de pasajeros ningún esclavo, ni blanco ni negro, a pesar de que algunos de ellos habían pisado ya suelo de las Indias para lucro y beneficio de sus amos. Su llamativa ausencia indica que los colonos confiaban todavía en que la mano de obra indígena hiciese los trabajos más duros, aunque es preciso señalar que no pocos trabajadores españoles fueron contratados — en apariencia - con el exclusivo fin de realizar las tareas de labrar la tierra y lavar el oro. En una época de tanteos y experimentos, casi todos fallidos, no puede sorprender esta indefinición o, por mejor decir, promiscua confusión de la mano de obra a emplear, unas veces española y otras taína ${ }^{6}$ o esclava.

El auge del comercio indiano favoreció la aparición de compañías de dos o más socios, uno de los cuales residía de manera permanente en la Española. En las escrituras que comentamos aparecen las compañías siguientes (el asterisco señala al compañero o factor en Indias, si así consta; la cifra indica el número de personas contratadas):

Álvaro y *Fernando de Briones, hermanos (10).

Andrés Cataño y *Diego de Alvarado (5).

Bernardo de Grimaldo y el jurado *García Tello y *Juan Fernández de las Varas (4). En un principio Grimaldo, todavía extranjero, actúa en nombre de los que son en realidad sus socios y con los que, como es sabido, acabó peleado ${ }^{7}$.

Luis Fernández y *Sancho López (4).

Pedro y Juan Daza, hermanos (2).

Juan de Cea, su hermano *Diego de Cea y su cuñado *Fernando de Córdoba (1). En 1506 la compañía de los tres parientes no pasaba por sus momentos mejores, pues Juan de Cea no había recibido ningún fruto de anteriores envíos a sus deu-

5 Así, por ejemplo, a Alonso de Hojeda se le dio licencia para pasar a Tierra Firme "seis esclavos blancos casados en estos nuestros reynos de Castilla" el 5 de octubre de 1503 (AGI, Indiferente General, 418, I, 139v).

6 Es lo que mandaron los reyes a Ovando en la instrucción que le dieron en Granada el 16 de setiembre de 1501: "porque para coger oro e fazer las otras labores que nos mandamos hazer será neçesario aprovecharvos del serviçio de los indios, conpelerlos heis a trabajar en las cosas de nuestro serviçio, pagando a cada uno el salario que justamente vos paresçiere que devieren de aver segund la calidad de la tierra" (AGI, Indiferente General, 418, I, 39v).

7 El rey había ordenado el 5 de enero de 1505 que los extranjeros que cargaban mercaderías para la Española lo hicieran "en conpañía de naturales e non ellos como prinçipales, e que los fatores sean naturales" (AGI, Indiferente General, 418, I, 149v). 
dos y factores; por ello Juan dio al menos dos poderes a su hermano Diego para tomar cuenta a Fernando de Córdoba de todas las mercancías que les había despachado a la Española ${ }^{8}$.

Juan de Palenzuela y *Francisco de Herrera (1).

Bernardino de Isla9 y Pedro García (1).

Entre los empresarios que al parecer actuaron en solitario descuella el baquiano Pedro de Uclés (9), seguido de Fernando de Porras (4), Juan Pérez (4) y Juan Martín (3). Más a la zaga quedan Alonso de la Barrera, Fernando de Herrera, Gonzalo de Corvera, Martín de Cáceres y Pedro Chacón con dos trabajadores, mientras que la mayoría (Francisco Jiménez, el piloto Francisco Niño, Francisco de Osuna, Gonzalo Fernández, Juan de Cardona, Juan Mill ${ }^{10}$, Lorenzo de Ahumada, Martín de Cáceres, Martín de Gamboa, Pablo de Ávila y Sancho López) se contentó con los servicios de un solo peón. Sorprende que una mujer, Marina Bernal, requiriese la asistencia de un jornalero, el carmonés Bartolomé de Carmona, en Puerto de Plata, la villa que en la costa septentrional de la isla hacía la competencia a Santo Domingo. Otra mujer, Juana, quizás una adolescente, se avino a su vez a ser la criada de un matrimonio, Juan de Cárdenas y Teresa Gómez.

De todas maneras, conviene extremar la cautela al enjuiciar los casos anteriormente citados, pues lo que a primera vista parece una iniciativa particular bien pudiera provenir de la decisión y capital de varios socios. Así, por ejemplo, consta que en 1503 Gonzalo de Corvera había hecho una compañía con el piloto Alonso Sánchez Roldán ${ }^{11}$; el 4 de setiembre de 1504 el mismo Corvera, probablemente gracias al dinero social, pudo enviar a la Española a seis personas para emplearlas tanto en sacar, apurar y lavar oro como en plantar heredades ${ }^{12}$. Es muy posible que la misma sociedad siguiera en vigor todavía en 1506. Por su parte, Pedro Chacón era un trapero conocido, propietario incluso de una nave llamada por su dueño la Chacona: ¿resulta creíble que arriesgara su persona yendo él mismo a las

8 7.1506, 418v: 19 de mayo; 10.1506: 26 de mayo.

9 Sobre este mercader véase Gil, J.: Conv. IV 253.

10 Ha de ser pariente (¿hermano?) del tintorero cordobés Diego Mill (1.1514, 2 [= 12], 483r: 14 de octubre). No me parece que este mercader pasara a la Española.

11 En efecto, el 4 de mayo de 1503 Roldán le dio poder en Santo Domingo para que lo pudiera obligar en Sevilla o en cualquier otra ciudad o villa hasta en cuantía de 600 castellanos, al plazo que quisiere y a quien quisiere. Fueron testigos de la escritura Diego de Escobar y Nicolás de Jerez (4.1504, 2, 378r). Corvera tomó prestados los 600 castellanos de Rodrigo de Carrión, según reconoció el 13 de setiembre de $1504(4.1504,2,397 \mathrm{v})$.

$124.1504,2,519 \mathrm{v}$. 
Indias? ¿No es más razonable pensar que tuviera un socio industrial en el Nuevo Mundo?

El contrato de trabajo, ya formulario, consta de dos cláusulas que especifican las obligaciones respectivas de las dos partes, la contratada y la contratante. Como muestra arquetípica he elegido una obligación cualquiera, a la que he quitado todas las referencias circunstanciales y he añadido indicación de las dos cláusulas principales:

(1) Yo... otorgo e conozco que entro a servir a soldada con vos... desde el día que yo llegare a la dicha isla Española al puerto de Santo Domingo fasta... años conplidos primeros siguientes, para que en este dicho tiempo yo, el dicho..., sirva a vos, el dicho..., e a quien vos mandardes, en el dicho mi ofiçio de... e en todas las otras cosas que me dixerdes e mandardes que a mí sean posibles fazer, así de noche como de día, en tal manera que, donde viere e supiere vuestro pro, vos lo llegue, e vuestro daño, que vos lo riedre; e si redrar no pudiere, que vos lo faga saber pérdida, daño o menoscabo que en vuestras cosas fiziere, a sabiendas que yo vos lo pague e peche por mí e por mis bienes, segund que el derecho manda.

(2) E que vos, el dicho..., seáys thenudo e obligado de me dar pasaje e mantenimiento fasta llegar a la dicha isla a vuestra costa e misión, e en la dicha isla me dedes en todo este dicho tienpo de los dichos... años comer e bever e casa e cama en qu'esté e duerma, sano o enfermo, segund estilo de la tierra; e más que me paguedes de soldada por cada un año de los dichos... años.... mrs. de moneda de la dicha isla, que me devedes dar en la dicha isla Española en paz e en salvo sin pleyto e sin contienda alguna en fin de cada un año de los dichos... años los dichos.... mrs., so pena del doblo... E con condiçión que, si en este dicho tienpo adoleçiere, que vos, el dicho..., seáys obligado de me curar e dar las medeçinas que oviere menester, desde el día que así adoleçiere fasta... [el tiempo de duración del contrato] primeros siguientes a vuestra costa e misión; e si más tienpo estoviere mal, que yo sea thenudo a me curar a mi costa e misión; e todos los días que falleçiere de vos servir d'este dicho tienpo por dolençia o por otro inpedimento, que, después del dicho tienpo cunplido, vos los sirva días por días e tienpo por tienpo... ${ }^{13}$

Mucho más interés tiene el segundo grupo, realmente extraordinario. En efecto, las actas notariales indican de manera irrefutable que una gran cantidad de personas pasó a Indias en ese año pagándose ellos mismos su pasaje, aunque entre ellas pudiese haber también algún asalariado (véase n. ${ }^{\circ}$ 7). Se puede concluir que la Española había dejado de ser un lugar inhóspito para convertirse en una tierra de promisión. Es muy llamativo, por otra parte, el hecho de que la inmensa mayoría de los emigrantes siguiera procediendo de Andalucía y de Extremadura. Parece como si las

13 15.1506, 923r-23v (contrato de Pedro, odrero). 
familias pobres andaluzas y extremeñas hubieran reunido sus últimos ahorros para enviar a alguno de sus retoños - $\mathrm{O}$ a varios amigos o familiaresa buscar allá en el Nuevo Mundo un alivio a su miseria, aprovechando que al frente de la gobernación se hallaba un extremeño, frey Nicolás de Ovando, más sensible a sus cuitas que un Cristóbal Colón.

Los viajeros, que se embarcaron en diferentes naos y carabelas (en la colonización española no hubo una Mayflower), pagaron por la travesía una suma variable, que oscila normalmente entre 8 y 13 castellanos por persona. A cargo del maestre corría darles mantenimiento y agua desde que la nave zarpara de Sanlúcar de Barrameda hasta que arribase al puerto de Santo Domingo. Sirva de muestra el contrato que hizo - pero no firmó; sólo pusieron su rúbrica los escribanos- el hombre más famoso de todos cuantos fueron este año a las Indias:

Sepan quantos esta carta vieren cómo yo, Fernando Cortés, fijo de Garçía Martínez Cortés $^{14}$, vezino de don Benito, tierra de Medellín, otorgo e conozco que devo dar e pagar a vos, Luys Fernández de Alfaro, vezino d'esta dicha çibdad, maestre de la nao que Dios salve que ha nonbre San Juan Bautista, que agora está en el puerto de las Muelas del río de Guadalquivir d'esta dicha çibdad, qu'estades presente, o a quien esta carta por vos mostrare e vuestro poder oviere, honze pesos de oro fundido e marcado, que son por razón del pasaje e mantenimiento que me devedes de dar en la dicha nao desde el puerto de Barrameda fasta la isla Española al puerto de la villa de Santo Domingo este viaje que agora va la dicha nao; e renunçio que non pueda dezir ni alegar que lo susodicho no fue e pasó así; e si lo dixere o alegare, que me non vala; los quales dichos honze pesos de oro me obligo de vos dar e pagar en la dicha isla Española en paz e en salvo, sin pleyto e sin contienda alguna, del día que la nao llegare... ${ }^{15}$

Como en las escrituras se especifica el nombre del maestre de la nave que recibió el dinero del pasaje, se puede hoy reconstruir a grandes rasgos la distribución de los pasajeros en el embarque y la fecha de su partida. Tuvo lugar de la siguiente manera:

1. Alonso Quintero (vecino de Palos, maestre de la nao Trinidad). Enero. Pasajeros: 2 (uno de ellos dudoso).

Alonso Martín. ¿Andrés Sotil?

14 La escritura parece indicar que el nombre del padre de Hernán Cortés —llamado en documentos posteriores Martín Cortés- era en realidad Garcí Martín Cortés.

15 4.1506, 3, 102r. El escribano dejó espacio en blanco para acabar los formularios jurídicos cuando tuviese tiempo y ganas o le pidiesen copia los interesados; y así quedó la escritura, incompleta y sin fecha, como la mayoría de estos contratos de pasaje. En el margen inferior se anota: "Reçibió dos ducados", quizá como señal. 
2. Alonso Rodríguez (maestre de la nao Santa María de la Antigua). Octubre.

Pasajeros: 1.

Bartolomé de Carmona.

3. Esteban de Guecho (vecino de Palos, maestre de la Santa María de la Rábida; la nao era mitad suya y mitad de Diego Rodríguez Prieto, alcalde mayor de Palos, véase 7.1506, 226r). Octubre.

Pasajeros: 2.

Juan Rodríguez y su mujer Isabel Díaz de Heredia.

4. Diego Rodríguez (vecino de Triana, maestre de la Santa Catalina). Mayo/junio. Los pasajeros hicieron los contratos en su mayoría con el cómitre Bartolomé Rodríguez, sobrino del maestre.

Pasajeros: 19.

Alonso Martínez.

Gonzalo Boadira.

Alfonso de Morales. Gonzalo Cermeño.

Alfonso Rodríguez. Gonzalo Jiménez.

Blas Morales. Juan de Godoy.

Diego Herrero. Juan Rodríguez Berrueco.

Fernando Martínez. Juan Sánchez Calatrava.

Fernando Zambrano. Leonor de Porras.

Fernando de Montoro. Pedro de las Garrovillas. Francisco. Pedro de Valera.

Francisco Ruiz. Tomás del Río.

Francisco de Villalón.

5. Diego Sánchez Colchero (vecino de Triana, maestre del Santa Ana). Setiembre/noviembre.

Pasajeros: 23.

Alfonso Díaz Trujillano.

Alfonso González Mendo y García Fernández Mendo.

Alonso Martínez.

Bartolomé Rodríguez.

Bernardino de Tapia y su mozo.

Cristóbal Domínguez.
Diego Martínez.

Fernando Martínez.

Fernando Sánchez Durán.

Fernando de Sepúlveda.

Francisco Fernández de Villalobos.

Francisco López. 
Gómez Nieto.

Pedro Álvarez.

Gonzalo Fernández de Utrera.

Pedro García.

Gonzalo Martínez.

Pedro de Medina.

Juan Fernández.

Pedro de Medina el Mozo.

Lope García Garabato.

6. Fernando de Bonilla (vecino de Triana, maestre de la nao Santa María de la Luz). Diciembre.

Pasajeros: 12.

Alonso García.

Alonso de Salamanca.

Francisco Sánchez Moreno.

Martín Sánchez de Tejares.

Gonzalo Ruiz.

Fernando Moreno.

Juan López de la Iglesia.

Fernando Vicente.

Miguel González.

Francisco Montesino.

Pedro Cobo.

Simón Ruiz Romero.

7. Francisco López (vecino de Sevilla [Santa María en la Cestería]), maestre de la nao San Pedro y San Pablo, propiedad de Francisco de Espíndola, alcalde de Medina Sidonia, véase 7.1506, 473r). En dos tandas: mayo/junio y noviembre/diciembre (señalo los pasajeros de la segunda con el número volado: ${ }^{2}$ ).

Pasajeros: 33 en el primer viaje y más de 13 en el segundo.

Alfonso de Campos.

Alfonso Gómez de Pineda.

Alfonso Jiménez.

Alfonso Rodríguez.

Alfonso de Ortega ${ }^{2}$ y su hijo Alfonso de Ortega el $\mathrm{Mozo}^{2}$.

Alfonso Sánchez de Castilleja.

Andrés Martínez.

Bartolomé Martínez.

Cristóbal Fernández.

Diego de Cáceres y su criado

Fernando Moreno.

Diego Jiménez 2 .

Diego Sánchez Ribero².
Fernando del Barco ${ }^{2}$.

Fernando Sobrino.

Francisco Durán².

Francisco de Heredia.

García de Miranda².

Gonzalo Izquierdo.

Gonzalo Lorenzo.

Isabel Gómez y sus hijas Juana y

Francisca.

Juan Caldera ${ }^{2}$.

Juan Esteban².

Juan Maldonado.

Juan Molano (o molinero).

Juan de Morales². 
Juan Pérez.

Pascual Maldonado.

Juan Sánchez de Requena.

Pedro del Guijo.

Juan Serrano.

Pedro Lorenzo.

Lucas Bejarano y su hermano

Pedro Martínez Carvajeda. Gonzalo.

Pedro Martínez Peña.

Luis Jiménez de Jaén con su Ruy Díaz de Vallejo y su hermamujer e hijas².

Martín de Cabra y su cuñado Pedro García.

Miguel de Ortega ${ }^{2}$. no Pedro García.

Sebastián Moreno.

$* * * 2$.

*** con su mujer e hijas ${ }^{2}$.

8. Juan Franco (vecino de Palos, maestre de la nao San Juan.) Mayo.

Pasajeros: 3 (dos de ellos dudosos).

Fernando de Herrera. Pedro Martínez. Fernando Sánchez.

9. Juan de Medina (vecino de Triana, maestre de la Santa María de la $L u z$, de la que era propietario Pedro Chacón). Agosto.

Pasajeros: 1

Francisco.

10. Juan Rodríguez Chocero (vecino de Palos, maestre del San Cristóbal). Marzo.

Pasajeros: 3.

Alonso Fernández Carvallón. Juan Martín. Pedro Muñoz.

11. Luis Fernández de Alfaro (vecino de Sevilla [Santa María en la Carretería], maestre del San Juan Bautista). Setiembre/diciembre. Varios contratos fueron hechos con el escribano de la nave, Juan de Llano.

Pasajeros: 15.

Alfonso Fernández.

Antón García y su hijo².

Antón Ronco, su mujer Elvira

Martínez y seis hijos e hijas.

Bartolomé Martín.
Diego Pérez².

Fernando Cortés.

Martín Corvo.

Ruy González². 
12. Sancho de Salazar (vecino de Rota, maestre del San Juan Bautista). Agosto/setiembre.

Pasajeros: 23.

Alfonso Fernández.

Alfonso Guiral.

Alfonso Jiménez.

Bartolomé de Arjona.

Benito Jiménez.

Catalina de la Mora y sus hijas

María, Beatriz y Ana.

Francisco López, su hermano

Francisco y su hijo Juan.

Juan Alfonso.

Juan López.
Juan Ramos.

Juan Ruiz.

Juan Ruiz de Montalvo.

María de Ortega y sus hijos Juan y Juana.

Pedro Gómez.

Pedro Ruiz.

Pedro de Torredonjimeno.

Pedro de Villagarcía.

Francisco Gómez Biduero.

Sorprende ciertamente este elevado número de aspirantes a colonos, incluso teniendo en cuenta que las lagunas de nuestra información son muy grandes. En efecto, nada sabemos sobre los pasajeros que fueron -o pudieron ir- en las naos San Jorge (maestre: Alonso Sarmiento), San Juan (maestre: Pedro Vallés), San Nicolás (maestre: Fernando de Morales), Santa Cruz (maestre: Alonso Cansino) o Santa María del Espinar (maestre: Juan Vinagre), por poner algún ejemplo. Las naves, por otra parte, solían hacer dos viajes al año a la Española, uno en primavera y otro en invierno. Tal parece haber sido el caso de la nao Santa María de la Luz, que tuvo a dos maestres distintos en cada travesía (Fernando de Bonilla y Juan de Medina); en cambio, la documentación apunta a que hubo dos naos que llevaron el mismo nombre (San Juan Bautista), la de Luis Fernández de Alfaro y la de Sancho de Salazar.

En cualquier caso, la gente debió de ir hacinada en la primera travesía de la nao de Francisco López. ¿Fallaron algunas personas de aquel verdadero tropel de 36 hombres y mujeres en el último momento? ¿Se suplieron con nuevos pasajes las bajas que pudieron causar el miedo al mar o una posible enfermedad, o bien esos puestos vacantes quedaron sin cubrir? Es arriesgado hacer cábalas. Pero hay que tener en cuenta que los emigrantes habían pagado el pasaje o parte del mismo por adelantado, y que nadie está dispuesto a perder dinero, de suerte que quien no se embarcaba, es de supo- 
ner que reclamase sus cuartos. Así ocurrió al menos una vez, según consta documentalmente. Pedro López y Pedro de León, vecinos de Solano, habían dado ya cuatro ducados a Pedro de Llano, el escribano del San Juan, por su pasaje y mantenimiento, cuando una enfermedad vino a aguarles sus sueños transocéanicos. Pues bien, los pobrecitos dolientes dieron poder a Juan Ortiz, vecino de Almendralejo, para reclamar el dinero entregado, que Llano devolvió religiosamente ${ }^{16}$. En otra ocasión, en el contrato de Ruy González y Diego Pérez con Luis Fernández de Alfaro, se señala que la escritura "no pasó", es decir, que no llegó a ratificarse.

Los documentos no indican el lugar que le fue asignado en la nave a cada pasajero. Cabe pensar que se habilitara un camarote para Leonor de Porras y su séquito y que los más pobres se acomodaran como buenamente pudiesen, pero nada consta. Sólo en escrituras más recientes se proporcionan más detalles, no sin motivo: el galeón tenía más cabida que la nao ${ }^{17}$. Resulta muy ilustrativo comparar la vaguedad de los contratos firmados en 1506 con la precisión de tres de los pasajes que dio en 1538 Miguel Ruiz de Ullán, maestre del galeón Santa María la Antigua, cargado en Sanlúcar de Barrameda con destino a San Juan de Ulúa. Así, el 4 de marzo el licenciado Lorenzo de Tejada, oidor de la Nueva España, se igualó con el maestre en 15.000 mrs. por una cámara "hecha en la chimenea a la vanda de a babor", así como en otros 24.000 mrs. por el flete de las doce personas que llevaba consigo, chicos o grandes, a razón de 2.000 mrs. cada uno ${ }^{18}$. A su vez, el 11 de marzo Alonso de la Serna, vecino "de la çibdad de México de la Nueva España de las Yndias del Mar Oçéano”, se comprometió a pagarle 99 ducados en total: 30 por el flete de una "cámara que en la dicha nao vos me dais a la vanda del castillete, cabe el cabestrante, a la vanda d'estibor [sic], e quarenta e ocho ducados por el pasaje de otras çinco presonas que comigo e de llevar, a razón de ocho ducados por persona, e los veinte e çinco restantes por el pasaje de tres esclavos negros que comigo e de llevar, e porque nos llevéis en ella fasta el puerto de San Juan de Lúa de la Nueva España e porque nos deis lugar en el dicho galeón en que lleve el

$164.1506,3,560 \mathrm{v}$. El poder (suelto; no lo encuentro ahora) fue otorgado el 25 de setiembre.

17 A veces el capitán cedía su camarote a un pasajero ilustre: así sucedió con la famosa embajada de los japoneses (véase Duarte de Sande, De missione legatorum Iaponensium ad Romanam curiam, rebusque in Europa, ac toto itinere animaduersis dialogus, Macao, 1590, pág. 365).

18 No pagaron flete el licenciado, su mujer y "una niña de teta hija mía". Tejada recibió un préstamo de 85 ducados por parte del guipuzcoano Miguel Ibáñez de Garagarza para el despacho de su persona y compañía, préstamo que se obligó a satisfacer en Veracruz al cabo de un mes de su llegada (15.1538 [= 9148]: 4 de marzo) 
matalotaje para mí e para las dichas presonas y esclavos"19. Por último, Diego de Zúñiga pagó el 11 de marzo 32 ducados por una "cámara debaxo de la puente" y otros 32 más por el pasaje de otras tres personas y lugar para el matalotaje ${ }^{20}$. De 1506 a 1538 la situación, más que cambiar, subió de nivel, como lo prueba el hecho de que aumentara el número de acompañantes y criados y que entre ellos figurasen algunos esclavos negros, probablemente llevados para su venta en el lugar de destino, no en balde habían transcurrido tres decenios entre las dos fechas.

Un enigma curioso plantea el paso de Hernán Cortés. Todas sus biografías antiguas coinciden en fechar su primer viaje a las Indias en 1504. Sin embargo, los protocolos hispalenses, como ya señaló Hugh Thomas ${ }^{21}$, atestiguan que el caudillo extremeño partió para el Nuevo Mundo en 1506. El error, si existe, pudo provenir de un fácil baile de letras $(j U d j v$ por $j U$ $d v j$ ). Más difícil de explicar es la grosera equivocación en la que habrían vuelto a incurrir los panegiristas cortesianos al dar el nombre del maestre de la carabela en la que se embarcó. Tanto la relación latina, debida muy probablemente a la pluma de Francisco López de Gómara ${ }^{22}$, como la Historia general de las Indias del mismo cronista ${ }^{23}$ indican que el maestre de la misma fue Alfonso Quintero y su piloto Francisco Niño, ambos vecinos de Palos. Ahora bien, en 1506 Francisco Niño fue el maestre de la nao Santa Clara, mientras que Alonso Quintero lo fue de La Trinidad; mas Cortés no hizo su contrato de embarque ni con uno ni con otro, sino con el maestre del San Juan Bautista, Luis Fernández de Alfaro, quien habría de ser uno de sus socios capitalistas en $1519^{24}$. Son quizá demasiados errores para que los cometiera un cronista serio y allegado al conquistador de México. La única manera posible de salvar la tradición historiográfica y el crédito de la biografía latina y la Historia castellana, que ofrece detalles del viaje que no parecen inventados, es que éste de 1506 fuera el segundo viaje de Cortés a la Española; efectivamente, Alonso Quintero zarpó a Indias

1915.1538 (= 9148), 701v. A. de la Serna le prometió pagarle la deuda en Veracruz en pesos de oro de la última fundición, al precio que allí entonces valiesen. Para su pasaje tomó prestados 107 ducados de Hernán Pérez, fiel ejecutor de Sevilla. Viajó también en el citado galeón Gonzalo de Salazar, factor del rey en la Nueva España.

$2015.1538(=9148), 703 \mathrm{v}$.

21 En su tan hermoso como sugestivo libro Conquest, Montezuma, Cortes, and the Fall of Old Mexico, Simon and Schuster, 1993, págs. 129-30.

22 Publicó esta biografía trunca, pero muy interesante, García Icazbalceta, J.: Colección de documentos inéditos para la Historia de México, ed. facsimilar, Porrúa, 1980, I, pág. 312 y siguientes.

23 Historia general de las Indias, II 2 (BAE 22, pp. 206-07)

24 Véase Gil, J.: Conv. III 147-48; sobre el maestre, mercader y jurado véase ibídem, III 226-27. 
en 1504 como maestre de La Trinidad, y bien pudo haber sido entonces su piloto Francisco Niño: el viaje historiado por las dos obras de Gómara.

En 1506 hubo menos compañías de las que se hubieran esperado en proporción a la afluencia de emigrantes. Gonzalo Díaz, un mercader de Lopera (Calatrava), se concertó con el sevillano Juan de Baena en los términos entonces usuales: Díaz había de pasar a Indias a vender las mercancías que le enviase Baena; iban a medias en la tercera parte de las ganancias, mientras que las dos terceras partes habrían de corresponder al mercader propietario de la mercancía, salvo que la misma perteneciese a Juan de Baena, a quien Díaz se comprometía a mandar diez pesos de oro todos los años 25 .

Más nuevo y curioso es otro tipo de negocio. Dado que la Española carecía de medicinas europeas, que era preciso suministrar desde Sevilla, el boticario sevillano Juan Bernal llegó a una serie de conciertos con dos colegas y paisanos a quienes sedujo la idea de tentar fortuna en Ultramar. Al primero, Gonzalo Fernández, le dio Bernal 20.000 mrs. en medicinas, drogas, aguas, confites y otras mercaderías ${ }^{26}$; al segundo, Juan de Jerez, 1.000 reales en medicinas, conservas y mercancías varias, que se cargaron en la nao Santa Catalina, de la que era maestre Alonso Cota ${ }^{27}$. Tanto Fernández como Jerez se comprometieron a abrir tienda en Indias, entregando la parte alícuota de las ganancias a Luis de Córdoba, estante en la Española, que era el representante de Bernal. En el primer caso, los socios iban a medias durante los dos años que habría de durar la compañía; en el segundo, las dos terceras partes de las ganancias correspondían a Bernal, que ponía también de su parte un mozo, quedando la tercera parte restante para Jerez. Pero resulta que este Jerez había residido ya en la Española, ya que en marzo de 1506, estando en Sevilla, fue preso en la cárcel del concejo por motivos que desconocemos. Alarmados por esta causa, los boticarios genoveses Jerónimo Barón y Antonio Castello encargaron al maestre Juan Rodríguez Chocero que reclamara un dinero que Jerez les debía en las Indias, "así el puerto de Santo Domingo como en otras partes"28, deuda contraída sin duda en una estancia anterior del moroso en la Española. Un boticario sevillano más pasó a Santo Domingo en 1506: Francisco de Zamora, a quien los mismos genoveses encomendaron el cobro de las deu-

253.1506 (21 de octubre).

26 4.1506, 3, 491r: 24 de setiembre.

27 4.1506, 3, 9r: 22 de julio.

28 4.1506, 1, 484r: 23 de marzo. 
das tanto del citado Juan de Jerez como de un Fulano de Medina, vecino de Sevilla pero residente en la Española ${ }^{29}$. Y aún otro boticario, Francisco Sánchez, vivía al menos desde 1506 en La Vega; también tenían correspondencia con él los citados Barón y Castello, que le enviaban sus productos a Puerto de Plata ${ }^{30}$. En la Española tampoco faltaban médicos, los llamados entonces "físicos", allí residía por aquellos años un galeno que se decía "maestre" Pedro de Oñate, "vezino de la villa de Santo Domingo"

La muchedumbre que pasó con Ovando en 1502 planteó al gobernador acuciantes problemas tanto de manutención como de alojamiento, por lo que el comendador solicitó de inmediato a los reyes que, mientras no hubiera mantenimientos, prohibieran la emigración a las Indias, petición que le fue concedida el 20 de marzo de 1503:

En lo que dezís que no vaya más gente de la que allá está por agora, porque no ay labranças para más, fasta que las aya, se hará como dezís ${ }^{32}$.

El gran número de personas llegadas en 1506 redobló los miedos de Ovando ante las posibles y nefastas consecuencias de tamaño aluvión demográfico. De ahí que el gobernador pidiera de nuevo que se frenara el aflujo de emigrantes, petición que sorprendió esta vez al rey. La contestación del monarca, que lleva fecha del 27 de octubre de 1507, fue un tanto sibilina, pues no dio ni quitó la razón a su gobernador, pero se reservó en cualquier caso la decisión final:

Lo que dezís que no se dexe ir de aquíi3 allá más gente, aunque sea de trabajo, fasta que la pidáis, bien quisiera yo saber por qué cabsa dezís que no vaya gente de trabajo, porque acá creído tienen que, quantos más trabajasen, mayor sería el ${ }^{34}$ provecho; pero, en fin, proveerse ha tanbién en esto como viéremos que más cunpla ${ }^{35}$.

29 4.1506, 5, 106r. Debía Medina a los genoveses 2.200 mrs.

30 4.1506, 1, 483r. El 23 de marzo de 1506 los genoveses dieron poder a Alfonso Núñez, maestre de La Garza de Santa María, para cobrar de Sánchez todos los mrs. que éste les debía de la mercancía llevada en otro viaje de la misma nao a Puerto de Plata.

31 4.1506, 3, 92r: 28 de agosto. Oñate recibió poder del platero Pedro de Garibay para presentarse en su nombre ante el gobernador Ovando, alcaides y justicias y presentarles una carta de receptoría del licenciado Rodrigo Guillén, teniente de asistente de Sevilla, así como pedir su cumplimiento.

32 Indiferente general, 418, I, 101v (CDIU V, pág. 49).

33 Después de "aquî" está tachado: "adelante".

34 Después de "el" está tachado: "trabajo". El escribano se distrae con frecuencia: como que tres líneas más abajo escribe "Aquino" por "Yáquimo".

35 AGI, Indiferente general, 1961, I, 4v (CDIU V, pág. 119). Véase: L. Arranz: Repartimientos y encomiendas en la Isla Española (El repartimiento de Alburquerque de 1514), Fundación García Arévalo, 1991, pág. 108; en general véase E. Mira Caballos: Nicolás de Ovando y los orígenes del sistema colonial español. 1502-1509, Santo Domingo, 2000, págs. 62-64. 
La honda transformación que, durante el gobierno de Ovando, había experimentado la Española para bien de los colonos se manifiesta sobre todo en el notable número de mujeres —-más de veinte, la mayoría sevillanas- que acudieron a embarcarse al puerto de las Muelas; las más pudientes, protegidas por un séquito de criados, las más pobres, acompañadas de un pariente o de un amigo de la familia. Como la isla, al parecer, había dejado de ser el lejano y bronco Oeste de los primeros tiempos colombinos, no pocos maridos mandaron llamar a sus mujeres, así lo hicieron el carpintero Martín Sánchez, el cuchillero Francisco Rodríguez, el alguacil Juan de Mata, el albañil García Rodríguez y Gaspar de Escobar; en 1506, todos ellos, al parecer, vieron finalmente satisfecho su deseo de reunirse con sus esposas e hijos. Además, otras cuatro mujeres cruzaron el Océano con sus respectivos maridos: Ana Fernández, Elvira Martínez, Teresa Gómez y dos más de nombre desconocido. Al menos diez niñas viajaron con sus padres o con su madre. Como ya se apuntó antes, una adolescente, Juana, fue como criada de un matrimonio. El elenco completo es el que sigue:

Ana Fernández, vecina de Sanlúcar la Mayor, mujer de Bartolomé Ramos.

Ana Rodríguez de Santa Ana, vecina de Sevilla (San Vicente), mujer del albañil García Rodríguez, estante en la Española.

Catalina de la Mora, vecina de Sevilla (Salvador), mujer del carpintero Martín Sánchez, estante en la Española, con sus hijas Ana, Beatriz y María.

Elvira Martínez, vecina de Sevilla (Santa Lucía), mujer de Antón Ronco, con seis hijos e hijas.

Isabel Gómez, vecina de Sevilla (Magdalena), mujer del cuchillero Francisco Rodríguez, estante en la Española, con sus hijas Francisca y Juana.

Isabel Díaz de Heredia, vecina de Sevilla (Magdalena), mujer del cordonero Juan Rodríguez.

Juana, hija de Pedro Mata, criada de Juan de Cárdenas y su mujer Teresa Gómez.

Leonor de Porras, vecina de Sevilla (Santa María), mujer de Juan de Mata, estante en la Española.

María de Ortega, vecina de Sevilla (Santa María), mujer de Gaspar de Escobar, estante en la Española, con su hija Juana.

Marina Bernal, vecina de Sevilla (San Miguel), mujer de Cristóbal Rodríguez Torres.

Teresa Gómez, vecina de Sevilla (Santa María), mujer de Juan de Cárdenas.

Mujer e hijas de Luis Jiménez de Jaén.

Mujer e hijas de $* * *$, vecinas de Sevilla (n. $\left.{ }^{\circ} 245\right)$.

Los oficios de los hombres que fueron a la Española son, por lo general, los de siempre: los obreros manuales, entre los que predominan el simple "trabajador", el "albañil" y el "labrador". No faltan tampoco oficios 
más especializados y raros, como un marinero que sabe manejar el bote pequeño llamado por su forma chinchorro ${ }^{36} \mathrm{y}$ un número inusitado de tejedores de todos tipos. Pero el cambio experimentado por la colonia empezó ya a exigir un nivel de educación más alto a los futuros pobladores, de este modo entre los pasajeros de 1506 figuran un portero de vara (sin duda, para guardia y ornato del cabildo), un mayordomo (es decir, un hombre experto en cuentas), un sacerdote, un bachiller y hasta tres boticarios. He aquí la lista completa (excluyo el "herrero" del n. 73 y el "pescador" de n. 200 , que interpreto como apellidos):

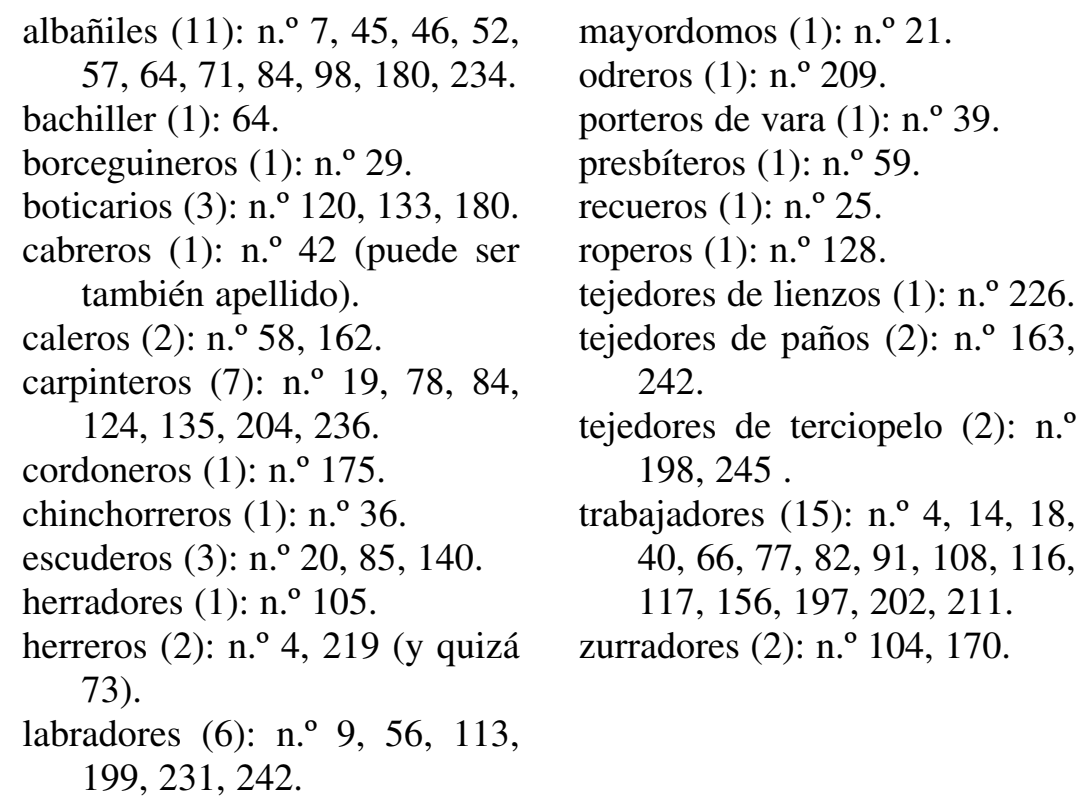

Poco o nada sé de la extracción social de estos hombres. Algunos tenían ya a sus espaldas una larga experiencia en tierra de las Indias, como Pedro de Uclés o Martín de Gamboa, a quien, por sus servicios, los

36 En un principio Ovando no dejó pescar a los vecinos de la Española, sin duda para controlar el mercado de abastos. Sin embargo, ante las quejas de los vecinos, desprovistos de mantenimientos, los reyes despacharon al gobernador el 20 de marzo de 1503 una orden taxativa: "que dexéis fazer a los vezinos de las dichas islas los varcos que quisieren para pescar en que pesquen con ellos libremente" (Indiferente general, 418, I, 101v [CDIU V, pág. 49]). A la pesca sin duda se iba a dedicar nuestro chinchorrero. 
Reyes Católicos habían nombrado contino; otros, chapetones, alcanzarán nombre y celebridad más tarde, como Fernando Cortés, el conquistador por antonomasia. La mayoría, sin embargo, no dejó huella hoy reconocible. Lo que sí es llamativo son las ínfulas de grandeza que se apoderaron de la gente, incluso muy humilde, cuando se decidió a cambiar de aires emprendiendo el viaje; así, Martín de Cáceres, un tejedor, oficio que desde los griegos era considerado despectivamente "mecánico", se convirtió de la noche a la mañana en un escudero. Llegados al Nuevo Mundo, no pocos hombres se pondrán nombres y apellidos vascos para presumir de nobleza antiquísima.

Es evidente que en esta turbamulta de pasajeros se colaron algunos conversos. Así, sospecho que el sevillano Lorenzo de Ahumada fuese un tío abuelo de Santa Teresa: recuérdese que con el correr de los años había de pasar a Indias un hermano de la santa, llamado también Lorenzo de Ahumada, y que otro tío abuelo, canónigo, el doctor Nuño Álvarez de $\mathrm{Cepeda}^{37}$, salió escapado de Sevilla para Roma nada más establecerse en esa ciudad la Inquisición. Marina Bernal nos trae a la mente el triste sino de otra Marina Bernal, reconciliada en Sanlúcar de Barrameda en $1514^{38}$. Sería también tentador relacionar al sevillano Tomás del Río con la familia del obispo de Scala, tan duramente castigada por el Santo Oficio; y a judío suena también el apellido Boadira que llevaba el compañero de Tomás, Gonzalo Boadira. Podrían tener asimismo ascendencia conversa Alfonso de Sevilla, Diego López, Diego Ruiz, Francisco Jiménez, Gonzalo Fernández, Juan de Jerez y Pedro de Valera; mas como no hay de ello pruebas contundentes, más vale prescindir de falsas conjeturas.

Era natural que así sucediese, incluso sin contar con el no pequeño aliciente que ofrecían las Indias como asilo del control inquisitorial. El comercio indiano, en efecto, atrajo muy pronto el interés de los grandes mercaderes conversos, que tuvieron que desplazarse por fuerza al Nuevo Mundo para vigilar la marcha de sus negocios. A los ejemplos que he estudiado en otra parte ${ }^{39}$ puedo añadir un caso más y precisamente de 1506 , el del sevillano Fernando de Ávila, hijo del contador de doña Catalina de Ribera Diego de Ávila, quien en su testamento, recordando deudas, trajo a

37 Véase Gil, J.: Conv. I 71. El padre Javierre me llamó muy oportunamente la atención sobre el parentesco de la santa con este Cepeda, parentesco que me había pasado inadvertido.

38 Véase Gil, J.: Conv. III 364.

39 Gil, J.: Conv. III 143ss. 
colación las sumas millonarias que le debía otro converso importante, Juan Sánchez (llamado de la Tesorería por su tío el tesorero aragonés), por su aportación de mercancías al comercio indiano:

Déveme el dicho Juan Sánchez de la Thesorería quatroçientas mill mrs. por un conosçimiento firmado de su nonbre, que son de las mercaderías e cosas que yo le vendí que tenía adereçadas para llevar a la isla Española... Declaro e digo que yo resçibí para llevar a la dicha isla Española de Miguel de Soria, vezino de la çibdad de Granada, çiertas cosas de mercaderías en un arca, que montaron sesenta mill e quatroçientos mrs., las quales cosas y la dicha arca yo le entregué al dicho Juan Sánchez entre las otras cosas que le vendí; e por razón del trabajo e industria que yo puse avía de aver çierta parte; y porqu'el dicho Juan Sánchez me dio de provecho en el presçio que con él hize a razón de treze por çiento, y quedando en mí la parte que del dicho provecho ove de aver, quedaron por del dicho Miguel de Soria sesenta e tres mill e quatroçientos e onze mrs., los quales dichos sesenta e tres mill e quatroçientos e onze mrs. mando que le sean pagados al dicho Miguel de Soria de los mrs. que se cobraren del dicho Juan Sánchez ${ }^{40}$.

A favorecer esa afluencia tan constante como solapada de los conversos hacia el Nuevo Mundo se unió otro factor más, el matrimonio de los emigrantes (de cristiandad nueva o rancia) con sevillanas de linaje poco limpio. Bastará dar un ejemplo: el notario apostólico Alonso de Jerez, marido de Francisca Ruiz, casó a sus dos hijas con dos indianos ilustres de los primeros tiempos, a Juana de Astorga con Pedro de Arbolancha y a Catalina Ruiz con Martín de Gamboa, encandilando a este último con una dote de 100.000 mrs. que no llegó a ser pagada nunca en su totalidad, quizá a causa de un revés económico causado por un malhadado encuentro con el Santo Oficio ${ }^{41}$. Converso es también el entorno de los Briones $^{42}$.

El paso de conversos a Ultramar trajo consigo, fatalmente, una secuela indeseada: el estiramiento del largo brazo de la Inquisición. Por un azar — la ida de Leonor de Porras - nos es conocida la estancia de Juan de Mata en la Española, alguacil del arzobispo de Sevilla. Ahora bien, Juan de Mata parece ser pariente — probablemente hermano- de Pedro de Mata, el

40 7.1506, 350v. Sobre la familia véase Gil, J.: Conv. III 284ss.

41 Como confesó la madre en su testamento, "yo le he pagado veinte e seis o veinte e siete mill, y demás d'estos creo que mi primo Johán Ximénez de Gatica, difunto, que Dios aya, le dio otros quatro o çinco mill" (5.1506, 395v: 21 de octubre). Una breve e incompleta noticia sobre la familia en Gil, J.: Conv. IV 283-85.

42 Gil, J.: Conv. III 382-83. 
alguacil de la Inquisición hispalense, casado en segundas nupcias con otra Porras, Ana de Porras ${ }^{43}$, muy probablemente se trate de un matrimonio de dos hermanos con dos hermanas. La presencia de Juan de Mata en Santo Domingo plantea un inquietante problema, pues no parece que lo hubiesen llevado a las Indias asuntos particulares, antes bien, da la impresión de que se encontraba allá por exigencias de su cargo - y el arzobispo de Sevilla era entonces Diego de Deza, el Inquisidor general- y de que su cometido se pensaba que habría de durar largo tiempo, tanto, que hizo necesario el traslado de toda la familia. Tal vez a causa de su diligencia cayó en manos del Santo Oficio Diego de Cea (para sus negocios en Indias véase más abajo s.v Francisco de Villalón), a quien le fueron confiscados los bienes antes de $1510^{44}$.

La procedencia geográfica de los pasajeros muestra que la emigración, como queda dicho, partió por lo general de Andalucía (y sobre todo de Sevilla y su tierra, a la que pertenecía entonces Encinasola) y de Extremadura (especialmente de la Baja Extremadura):

\section{ANDALUCÍA}

Arahal (El). 1: Blas Morales.

Arjona. 5: Bartolomé de Arjona. Francisco López, su hermano Francisco y su hijo Juan. Juan Ruiz.

Aznalcázar. 1: Diego Andrés.

Benalcázar. 1: Francisco Gómez Biduero.

Bollullos de la Mitación. 1: Martín Bogado.

Carmona. 2: Bartolomé de Carmona. Francisco Montesino.

Cazalla de la Sierra. 1: Juan Maldonado.

Córdoba. 3: Juan Mill. Sancho de Buenosvinos el Mozo. Juan de la Torre.

Écija. 1: Francisco de Osuna (?).

Encinasola. 2: Diego Pérez. Ruy González.

Fuente de Pero Abad (La). 1: Pedro Ruiz.

Granada. 1: Fernando de Sepúlveda Cabeza.

Guadalcanal. 4: Alfonso Rodríguez. Francisco de Heredia. Gonzalo Jiménez. Juan Rodríguez Berrueco.

Huévar. 2: Cristóbal Fernández. Gonzalo Izquierdo.

43 Gil, J.: Conv. II 269-70.

44 Gil, J.: Conv. III 495. 
Jaén. $4+\mathrm{x}$ : Luis Jiménez de Jaén $\mathrm{y} * * *$, con sus mujeres e hijos.

Jerez de la Frontera. 1: Juan Pago.

Lopera. 1: Gonzalo Díaz.

Lucena. 1: Alonso Fernández Carvallón.

Manzanilla. 1: Antón de Alcántara.

Montoro. 1: Fernando de Montoro.

Niebla. 1: Gonzalo Cermeño.

Osuna. 1: Ruy Díaz.

Palma (La). 1: Bartolomé cabrero.

Palos. 2: Andrés Sotil. Juan Martín.

Rianzuela. 2: Alfonso de Ortega. Alfonso de Ortega el Mozo.

Rota. 1: Pedro Gómez.

Sanlúcar la Mayor. 17: Alfonso de Campos. Alfonso Jiménez. Alfonso Sánchez de Castilleja. Bartolomé Ramos y su mujer Ana Fernández. Fernando Martínez. Fernando Zambrano. Francisco. Gonzalo. Lucas Bejarano y su hermano Gonzalo. Martín de Cabra y su cuñado Pedro García. Pedro Martínez Peña. Ruy Díaz de Vallejo y su hermano Pedro García.

Sevilla. 33: Alejo de Medina. Alonso de la Barrera. Alfonso Fernández. Alonso Martínez. Alfonso de Morales. Alonso de Ocaña. Alfonso de Sevilla. Álvaro de Briones. Ana Rodríguez de Santa Ana. Antón Ronco, su mujer Elvira Martínez y seis hijos. Antón Vázquez. Antonio de Torres. Bartolomé Fernández. Bartolomé García. Bartolomé Rodríguez. Benito Maldonado. Bernal Sánchez. Catalina de la Mora y sus hijas María, Beatriz y Ana. Cristóbal Vázquez. Diego Costa. Diego García. Diego López. Diego Ruiz. Fernando de Porras. Francisco. Francisco Jiménez. Francisco de Zamora. Gómez Bernal. Gonzalo de Baena. Gonzalo de Corvera. Gonzalo Fernández. Gonzalo Fernández. Gonzalo Suárez. Isabel Gómez. Juan de Cárdenas y su mujer Teresa Gómez. Juan de Godoy. Juan de Jerez. Juan López. Juan Pérez. Juan Rodríguez y su mujer Isabel Díaz de Heredia. Juan Sánchez de Requena. Leonor de Porras. Lorenzo de Ahumada. Luis Fernández. María de Ortega y sus hijos Juan y Juana. Marina Bernal. Martín de Cáceres. Martín de Gamboa. Martín Sánchez. Pascual Maldonado. Pedro, odrero. Pedro Chacón. Pedro de Valera. Tomás del Río. Un hombre de nombre desconocido (244).

Tocina. 2: Diego de la Trinidad. Juan Sánchez Galindo.

Torre del Campo. 2: Juan López de la Iglesia. Simón Ruiz Romero.

Torredonjimeno. 1: Pedro de Torredonjimeno (151).

Utrera. 2: Fernando Martínez de Utrera. Martín Fernández Pescador.

Villanueva (¿del Ariscal? ¿de la Serena?). 1: Antón García.

Villanueva del Ariscal (escrito: Aliscar). 2: Alfonso Gómez de Pineda. Pedro Martínez Carvajeda.

Villaverde. 2: Miguel de Ortega. Juan de Morales. 


\section{EXTREMADURA}

Alburquerque. 3: Bartolomé Rodríguez. Fernando Sánchez Durán. Gómez Nieto. Alcántara. 5: Alfonso Díaz Trujillano. Martín Corvo (?). Pedro Álvarez. Pedro de Medina. Pedro de Medina el Mozo.

Alguijuela de Salvatierra (no encuentro en el Diccionario de Madoz el primer topónimo, de lectura muy clara, ni buscándolo por Arguij- ni por Guij-; me parece extremeño). 1: Alonso García.

Almendral. 3: Cristóbal Domínguez (36). Juan Fernández (97). Pedro García (139).

Almendralejo. 1: Pedro de Ortigosa.

Arroyo del Puerco. 1: García Fernández Mendo (72).

Azuaga. 1: Pedro de Azuaga. Pedro Martínez de la Baquera (145).

Badajoz. 6: Alfonso Jiménez. Francisco Fernández de Villalobos. Francisco López. Gonzalo Fernández de Utrera. Juan Esteban. Lope García Garabato.

Cáceres. 5: Andrés Martínez. Bartolomé Martín. Fernando Vicente. Juan Pérez. Sebastián Moreno.

Casar de Cáceres. 1: Benito Jiménez.

Coria de Galisteo. 1: Diego de Cáceres.

Don Benito. 2: Diego Lozano. Fernando Cortés.

Fregenal. 1: Juan Sánchez Calatrava.

Fuentes. 2: Francisco Sánchez Moreno. Miguel González.

Garrovillas (Las). 10: Alfonso González Mendo. Bartolomé Martínez. Diego Jiménez. Diego Sánchez Ribero. Francisco Durán. Gonzalo Lorenzo. Juan Caldera. Juan Molano. Pedro de las Garrovillas. Pedro Lorenzo.

Hera de Hornachos (La). Alonso Viejo. Francisco Fernández.

Medellín. 4. Juan. Juan Daza. Pedro Daza. Pedro García.

Mérida. 3: Felipe Vázquez. Juan Alfonso. Juan Ramos.

Montánchez. 4: Alfonso Sánchez. Diego Fernández del Coso. Juan de la Parra. Martín Muñoz.

Moraleja (La). 2: Juan Serrano. Pedro del Guijo.

Oliva (La). 1: Fernando Martín de la Oliva.

Puebla del Maestre (La). 3: Alfonso Fernández. Alfonso Guiral. Juan López.

Ribera.1: Alfonso Rodríguez.

Santos de Maimona (Los). 1: Diego Martínez.

Torrejoncillo.3: Alonso Martínez. Fernando Martínez. Gonzalo Martínez.

Trujillo. 2: Alfonso Martínez. García de Miranda.

Turajada (no localizo el topónimo, escrito muy claramente, en el Diccionario de Madoz). 1: Bartolomé González. 
Usagre.1: Juan Antón.

Valverde. 1: Felipe Vázquez.

Villanueva de la Serena. 1. Bartolomé Sánchez de la Molinera.

Zalamea del Arzobispo. 1: Sebastián Alonso.

Zarza de Alhanje (La). 2: Fernando Sánchez. Pedro Martínez.

Zufre. 1: Alonso.

\section{OTROS LUGARES DE ESPAÑA}

Aldea del Obispo. 1: Juan

Aldehuela. 1: Bernardino de Tapia.

Aranda de Duero.1: Juan Gutiérrez de Aranda.

Asturias. 1: Juan Avana.

Ávila. 1: Fernando del Barco.

Carrión de los Condes. 1: Juan Fraile.

Ciudad Real. 1: Fernando de Herrera.

Coruña (La). 1: Fernando Sobrino.

Chinchón. 1: Pascual Maldonado.

Guadalajara. 1: Diego de Talamanca.

Madrid. 1: Pablo de Ávila.

Orgaz. 1: Alonso Martín.

Sahagún. 1: Francisco Ruiz.

Salamanca. Martín Sánchez de Tejares.

San Martín de Valdeiglesias. 1: Cristóbal Ruiz.

Talavera de la Reina. 2: Alonso Rodríguez. Juan Sánchez de Talavera.

Valdepeñas.1: Juan Fernández de Valdepeñas.

Villagarcía (¿de Campos? ¿de Arosa?). 1: Pedro de Villagarcía.

Villalón. 1: Francisco de Villalón (?).

Villanueva de los Infantes. 1: Francisco Fernández de Ocaña.

\section{NO LOCALIZADOS}

Mormenda (La). 1: Ginés Martínez.

Véase Alguijuela de Salvatierra. Turajada. 


\section{LISTA ALFABÉTICA DE PASAJEROS}

1. Alejo de Medina, vecino de Sevilla (San Lorenzo). Véase Benito Maldonado.

2. Alonso, natural de Zufre, hijo de Pedro Sánchez. Véase Bartolomé, cabrero.

3. Alonso de la Barrera, vecino de Sevilla (Santa María, San Nicolás), hijo del licenciado Francisco de la Barrera (Gil, J.: Conv. III 331). Contrata a *Diego Costa y a *Juan Sánchez Galindo. Sale garante ante los oficiales de la Casa de la Contratación de que el maestre Alonso Cota daría buena cuenta del viaje y tornaviaje de su navío (4.1506, 3, 460r: sin fecha). Véase * Antonio de Torres.

4. Alfonso de Campos, herrero, y Alfonso Jiménez, trabajador, vecinos de Sanlúcar la Mayor: 22 castellanos a Francisco López por los dos (4.1506, 2, $1 \mathrm{v})$.

5. Alfonso Díaz Trujillano, vecino de Alcántara. Véase Pedro de Medina.

6. Alfonso Fernández, vecino de La Puebla del Maestre, hijo de Martín Fernández: 36 pesos a Sancho de Salazar por él y por Alfonso Guiral y Juan López, también vecinos de La Puebla (4.1506, 3, 427r).

7. Alfonso Fernández, albañil, vecino de Sevilla (San Lorenzo), marido de Francisca Fernández. 20-5: con Álvaro y Fernando de Briones. 2 años. 12.000 mrs. (15.1506, 2,10r). 12 pesos a Luis Fernández de Alfaro (4.1506, $3,534 \mathrm{r})$.

8. Alonso Fernández Carvallón, vecino de Lucena. Véase Pedro Muñoz.

9. Alonso García, labrador, vecino del Alguijuela de Saltavierra (ducado de Alba). 23-12: 9 castellanos a Fernando de Bonilla (15.1506, 2, 1.062r).

10. Alfonso Gómez de Pineda, vecino de Villanueva del Ariscal. Véase Pedro Martínez Carvajeda.

11. Alfonso González Mendo, vecino de las Garrovillas, y García Fernández Mendo, su hermano, vecino de Arroyo del Puerco: 20 castellanos a Diego Sánchez Colchero por los dos (4.1506, 3, 563r).

12. Alfonso Guiral, vecino de la Puebla del Maestre. Véase Alfonso Fernández.

13. Alfonso Jiménez, vecino de Badajoz. Véase Benito Jiménez.

14. Alfonso Jiménez, trabajador, vecino de Sanlúcar la Mayor. Véase Alfonso de Campos.

15. Alonso Martín, vecino de Orgaz, hijo del trapero Pedro Fernández (m.), y de Marina López. 27-1: antes de partir en la nao de Alonso Quintero, vecino de Palos, hace testamento. Quiere que lo entierren, de morir en Sevilla, en la iglesia de San Isidoro. Dispone que, a su fallecimiento, Juan Gómez, vecino de Orgaz, venda sus mercancías en las Indias y entegue el fruto de la venta a su madre, a la que deja por heredera. Nombra albacea al odrero Juan de Carrión, vecino de Sevilla (San Isidoro). Recuerda haber dado a Alonso Quintero 9 ducados por el flete de su carga $(15.1506,1,122$ r). 
16. Alfonso Martínez, natural de Trujillo. Véase Diego Herrero.

17. Alonso Martínez, vecino de Torrejoncillo. Véase Fernando Martínez.

18. Alonso Martínez, trabajador, vecino de Sevilla (San Vicente), marido de Elvira Fernández. 15-5: con Álvaro y Fernando de Briones. 2 años. 5.000 mrs., de los que recibe adelantados 1.500 mrs. (15.1506, 1, 1.043r). 26-6. Lo avala Francisco López, tejedor de lienzos, vecino de Sevilla en la colación de la Magdalena $(15.1506,1,869$ r).

19. Alfonso de Morales, carpintero, vecino de Sevilla (Salvador), hijo de Cristóbal de Morales: 8 castellanos a Diego Rodríguez (4.1506, 2, 354r).

20. Alonso de Ocaña, escudero, vecino de Sevilla (San Esteban). Hace compañía con *Martín de Cáceres.

21. Alfonso de Ortega, mayordomo de doña María Buenavía, y su hijo Alfonso de Ortega el Mozo, vecinos de Rianzuela (arzobispado de Sevilla): 6 castellanos a Francisco López por los dos $(4.1506,3,57 \mathrm{r})$.

22. Alfonso de Ortega el Mozo, hijo de *Alfonso de Ortega.

23. Alfonso Rodríguez, natural de Guadalcanal. Véase Juan Sánchez Calatrava.

24. Alonso Rodríguez, natural de Talavera de la Reina. Véase Pedro de Ortigosa.

25. Alfonso Rodríguez, recuero, vecino de Ribera (Orden de Santiago): 1.500 mrs. a Francisco López (4.1506, 2, 763r).

26. Alonso de Salamanca, vecino de Plasencia, y Martín Sánchez de Tejares, vecino de Salamanca. 23-12: 7.010 mrs. a Fernando de Bonilla (15.1506, 2, 1.063r).

27. Alfonso Sánchez, vecino de Montánchez, hijo de Pedro Sánchez Duque: con Pedro de Uclés. 2 años. 4.000 mrs. (4.1506, 3, 374r).

28. Alfonso Sánchez de Castilleja, vecino de Sanlúcar la Mayor (Santa María), marido de Inés Rodríguez de Montesdoca: 9 castellanos a Francisco López (4.1506, 2, 41r).

29. Alfonso de Sevilla, borceguinero, vecino de Sevilla (Salvador), hijo de Juan Cofrade. 6-6: con Pedro de Uclés. 2 años. 6.000 mrs. (4.1506, 2, 425r).

30. Alonso Viejo, vecino de la Hera de Hornachos. 25-1: con Fernando de Porras. 2 años. 5.000 mrs. (5.1506, 217r).

31. Álvaro de Briones, mercader, vecino de Sevilla (Santa María). Su hermano Fernando estaba ya en las Indias (Gil, J.: Conv. III 382-83). Contrata a *Alfonso Fernández, a *Alfonso Martínez, a *Antón Vázquez, a *Bartolomé García, a *Bartolomé Rodríguez, a *Bernal Sánchez, a *Cristóbal Vázquez, a *Gómez Bernal, a *Juan López y a *Martín Sánchez. 6-7: Lleva fletadas 30 toneladas (20 de madera y 10 de mercaderías, a $2.000 \mathrm{mrs}$. la tonelada) y una yegua con su aparejo y mantenimiento (por $6.000 \mathrm{mrs}$.) en la nao San Juan de Cristóbal Vallés, vecino de Palos (15.1506, 2, 178v).

32. Ana, hija de *Catalina de la Mora, vecina de Sevilla.

33. Ana Fernández, vecina de Sanlúcar la Mayor, mujer de *Bartolomé Ramos. 
34. Ana Rodríguez de Santa Ana, vecina de Sevilla (San Vicente), mujer del albañil García de Salas, estante en la Española. 18-6: su marido la había mandado llamar con *Juan Sánchez de Requena, ofreciendo que Sánchez "le comprase çiertas joyas... de çiertos mrs. qu'el dicho su marido le dio. Ella dixo que quería e le plazía de ir con el dicho Juan Sánchez de Requena a las dichas Yndias a poder del dicho su marido; e que si no fuere, qu'el dicho Juan Sánchez haga pago al dicho su marido con la ropa que conprare" $(10.1506,35 \mathrm{v})$.

35. Andrés Martínez, vecino de Cáceres. Véase Sebastián Moreno.

36. Andrés Sotil, chinchorrero, vecino de Palos. 7-1: con Miguel Díaz y Francisco de Garay, vecinos de la Española, y el mercader Juan Antonio Colombo (el sobrino de Cristóbal Colón). 2 años. 18.000 mrs., de los que Juan Antonio le entrega 9 ducados de adelanto. Da por fiador a Alonso Quintero, vecino de Palos, maestre de la nao La Trinidad (15.1506, 1, 59r)

37. Antón de Alcántara, vecino de Manzanilla, hijo de Juan Pérez de Alcántara. 25-1: con Fernando de Porras. 2 años. 5.000 mrs. ( 217r).

38. Antón García, vecino de Villanueva: 3.000 mrs. a Luis Fernández de Alfaro por él y su hijo $(4.1506,5,194 r)$

39. Antón Ronco (mejor que Rouco), portero de vara, vecino de Sevilla (Santa Lucía): 1.500 mrs. a Luis Fernández de Alfaro por él, su mujer Elvira Martínez y sus hijos e hijas, en total ocho personas (4.1506, 3,101r).

40. Antón Vázquez, trabajador, vecino de Sevilla (San Román), marido de Aldonza Fernández. 16-5: con Álvaro y Fernando de Briones. 2 años. 4.000 mrs., de los que recibe adelantados 1.500 mrs. (15.1506, 1, 1.061v). 27-5: Lo avala Diego de Córdoba, trapero, vecino de Triana (15.1506, 1, 870r).

41. Antonio de Torres, vecino de Sevilla (San Juan), hijo de Cristóbal de la Torre (m.), vecino de Sevilla (Omnium sanctorum). 8-6: reconoce deber a Alonso de la Barrera, vecino de Sevilla (San Nicolás), hijo del licenciado Francisco de la Barrera, 8 castellanos que éste le había prestado para pagar su pasaje a las Indias $(5.1506,272 \mathrm{v})$.

42. Bartolomé, cabrero, natural de La Palma (lugar del conde de Cabra), hijo de Domingo Juan, cabrero, y Alonso, natural de Zufre, hijo de Pedro Sánchez. 4-6: con Andrés Cataño, vecino de Sevilla (Santa María), y su socio Diego de Alvarado, estante en la isla Española. 3 años. 6.000 y 4.000 mrs. respectivamente. Dan fe de su identidad Pedro Sánchez de Almendralejo, natural de Almendralejo, y Alonso de Talavera, natural de Talavera de la Reina $(15.1506,1,927 \mathrm{v})$.

43. Bartolomé de Arjona, vecino de Arjona, hijo de Pedro Sánchez de Arjona, y Pedro de Torredonjimeno, hijo de Diego Fernández, vecino de Torredonjimeno: 22 pesos a Sancho de Salazar por los dos (4.1506, 3, 328v).

44. Bartolomé de Carmona, vecino de Carmona, con Marina Bernal, vecino de Sevilla (San Miguel), mujer de Cristóbal Rodríguez Torres: 3-3 ["febrero" 
dice la escritura, error del escribano por "marzo"]). 2 años en Puerto de Plata.10.000 mrs. Su nao es la Santa María de la Antigua (3.1506).

45. Bartolomé Fernández, albañil, vecino de Sevilla (San Martín), marido de Isabel Fernández. 23-5: con Bernardo de Grimaldo para servir en Indias al jurado García Tello y a Juan Fernández de las Varas “en el dicho mi ofiçio de albañí e en lo de carpintero, en lo que yo sé de carpintero, e en las otras cosas que yo supiere". 2 años. 12.000 mrs. (7.1506, 433r).

46. Bartolomé García, albañil, vecino de Sevilla (San Vicente). 15-5: con Álvaro y Fernando de Briones. 2 años. 12.000 mrs. Recibe adelantados 4.000 mrs. $(15.1506,1,1.039 \mathrm{v})$.

47. Bartolomé González, vecino de Turajada (condado de Medellín), hijo de Juan Fernández Sacristán. 20-4: con el mercader Fernando de Herrera. 2 años. 4.000 mrs. (10.1506, 9v). Es mayor de 20 años y menor de 25.

48. Bartolomé Martín, vecino de Cáceres, hijo de Juan Martín Monrovel. 8-10: paga a Juan Cordero, vecino de Cáceres, 11 pesos para que éste lo lleve a la Española en la nao de que era señor (error por "escribano") Pedro de Llano (15.1506, 2, 804r).

49. Bartolomé Martínez, vecino de las Garrovillas. Véase Pedro Lorenzo.

50. Bartolomé Ramos, vecino de Sanlúcar la Mayor, y su mujer Ana Fernández. 12-8: con el jurado García Tello y Juan Fernández de las Varas (la mujer los ha de servir "en regir vuestras casas e coser e labrar e en todas las otras cosas de serviçio de casa". 2 años. 7.000 mrs. Bernardo de Grimaldo les adelanta 2.000 mrs. (7.1506, 530r).

51. Bartolomé Rodríguez, vecino de Alburquerque. Véase Gómez Nieto.

52. Bartolomé Rodríguez, albañil, vecino de Sevilla (San Lorenzo), marido de Isabel García. 15-4: con Álvaro y Fernando de Briones. 2 años. 5.500 mrs. (15.1506, 1, 1.041r).

53. Bartolomé Sánchez de la Molinera, vecino de Villanueva de la Serena, hijo de Bartolomé Sánchez de la Molinera. 5-2: con el bachiller Cristóbal Ruiz, vecino de San Martín de Valdeiglesias. 3 años. 6.800 mrs.en total (15.1506, $1,283 \mathrm{v})$.

54. Bartolomé de Utrera, vecino de Utrera. 17-1: con Juan Alemán (el nombre corregido sobre "Pedro"). 2 años. 5.500 mrs. (11.1506).

55. Beatriz, hija de *Catalina de la Mora, vecina de Sevilla.

56. Benito Jiménez, labrador, vecino del Casar de Cáceres, y Alfonso Jiménez, vecino de Badajoz: 24 pesos a Sancho de Salazar por los dos (4.1506, 3, $559 \mathrm{v})$.

57. Benito Maldonado, albañil, vecino de Sevilla (San Vicente), y Alejo de Medina, vecino de Sevilla (San Lorenzo). 2-8: con Martín de Cáceres, tejedor de terciopelo, vecino de Sevilla (San Vicente). 2 años. $6.000 \mathrm{mrs}$. (4.1506, 5, 95r). 
58. Bernal Sánchez, calero, vecino de Sevilla (San Esteban). 20-6: con Alvaro y Fernando de Briones, obligándose a llevar "una almádena e dos horquillos para fazer el dicho serviçio". 2 años. $10.500 \mathrm{mrs}(15.1506,2,13 \mathrm{v})$.

59. Bernardino de Isla. Junto con Pedro García contrata a *Juan, hijo de Fernando Vázquez.

60. Bernardino de Tapia, bachiller, clérigo presbítero, vecino de La Aldehuela (Salamanca): 20 castellanos a Diego Sánchez Colchero por él y un mozo, así como 2.000 mrs. por el flete de dos líos y una caja que había de llevar "ençima de cubierta" (4.1506, 5, 227r).

61. Blas Morales, vecino de El Arahal: 9 castellanos a Diego Rodríguez (4.1506, 2, 267r).

62. Catalina de la Mora, vecina de Sevilla (Salvador), mujer del carpintero Martín Sánchez, estante en la Española: 48 pesos a Sancho de Salazar por ella y sus hijas María, Beatriz y Ana (4.1506, 3, 428v).

63. Cristóbal Domínguez, hijo de Gonzalo Domínguez, Juan Fernández y Pedro García, vecinos de Almendral (condado de Feria): 30 castellanos a Diego Sánchez Colchero por los tres (4.1506, 3, 566r).

64. Cristóbal Fernández, albañil, vecino de Huévar, marido de Antonia Fernández: 9 castellanos a Francisco López (4.1506, 2, 4.1506, 2, 729r y 740v).

65. Cristóbal Ruiz, bachiller, vecino de San Martín de Valdeiglesias. Contrata a *Bartolomé Sánchez de la Molinera.

66. Cristóbal Vázquez, trabajador, vecino de Sevilla (San Vicente), marido de Catalina Manuel. 20-5: con Álvaro y Fernando de Briones. 2 años. 4.500 mrs. $(15.1506,2,11 \mathrm{v})$.

67. Diego Andrés, vecino de Aznalcázar, hijo de Pedro Andrés. 3-8: con Martín de Gamboa, vecino de Sevilla (Santa María). 2 años. 6.000 mrs. (4.1506, 5, 108v).

68. Diego de la Bastida, estante en Sevilla, hijo de Pedro Martínez de la Bastida y de Catalina Alonso. 22-5: con Juan Pérez, vecino de Sevilla. 2 años y medio. 10.000 mrs. (11.1506).

69. Diego de Cáceres, vecino de Coria de Galisteo, con su criado Fernando Moreno. 13-7: 16 castellanos a Francisco López por los dos (4.1506, 2, 612r; véase 645r).

70. Diego Costa, vecino de Sevilla (Santa María), marido de Beatriz de Torres. 25-6: con Alonso de la Barrera, hijo del licenciado Francisco de la Barrera, y con el primo de éste, Francisco del Castillo, estante en la Española. 2 años. 5.000 mrs. $(5.1506,284 r)$.

71. Diego Fernández del Coso (o tal vez Castillo), vecino de Montánchez: con Pedro de Uclés. 2 años $(4.1506,3$, 375r).

72. Diego García, albañil, vecino de Sevilla (San Vicente), marido de Marina Vázquez. 23-5: con Bernardo de Grimaldo para servir en Indias al jurado 
García Tello y a Juan Fernández de las Varas "en el dicho mi ofiçio de albañí e en el de carpintero, en lo que yo sé de carpintero e en las otras cosas que yo supiere de mi engenio, así de fazer hornos e ladrillo e cal e teja como en las otras cosas que yo supiere". 2 años. 12.000 mrs. (7.1506, 432v).

73. Diego Herrero y Alonso Martínez, naturales de Trujillo: 10 ducados "en cumplimiento de pago de 20 ducados" a Diego Rodríguez por los dos (4.1506, 2, 471r).

74. Diego Jiménez, vecino de las Garrovillas. Véase Diego Sánchez Ribero.

75. Diego López, vecino de Sevilla. Había de servirle *Juan Sánchez de Talavera.

76. Diego Lozano, vecino de Don Benito, hijo de Diego Lozano: con Pedro de Uclés. 2 años. 4.000 mrs. (4.1506, 3, 441v).

77. Diego Martínez, trabajador, vecino de Los Santos de Maimona (Orden de Santiago), marido de Inés Vázquez: 10 castellanos a Diego Sánchez Colchero (4.1506, 3, 312r).

78. Diego Pérez, vecino de Encinasola. Véase Ruy González. No pasó la escritura.

79. Diego Ruiz, carpintero, vecino de Sevilla (San Lorenzo), hijo del corredor de lonja Juan Ruiz: con Pedro de Uclés. 2 años. 8.000 mrs. (4.1506, 2, 269r).

80. Diego Sánchez Ribero, Juan Caldera, Francisco Durán y Diego Jiménez, vecinos de las Garrovillas: 44 castellanos a Francisco López por los cuatro (4.1506, 5, 187r).

81. Diego de Talamanca, natural de Guadalajara, hijo de Gonzalo Bienquerencia. 21-1: con el piloto Francisco Niño, vecino de Moguer. 2 años. 5.000 mrs. (3.1506).

82. Diego de la Trinidad, trabajador, vecino de Tocina. 17-9: con el mercader Pedro Chacón, vecino de Sevilla. 2 años. 2.000 mrs. más "un capote nuevo de sayal e una camisa d'estopa" (11.1506).

83. Elvira Martínez, mujer de *Antón Ronco, vecino de Sevilla.

84. Felipe Vázquez, albañil y carpintero, vecino de Valverde (Mérida). 7-8: con el trapero Pedro Chacón. 1 año. 5.000 mrs. (15.1506, 2, 419r:).

85. Fernando del Barco, escudero, vecino de Ávila, marido de Isabel Gómez: 11 castellanos a Francisco López (4.1506, 5, 209r).

86. Fernando Cortés, hijo de García Martínez Cortés, vecino de Don Benito (tierra de Medellín): 11 pesos a Luis Fernández de Alfaro (4.1506, 3,102r).

87. Fernando de Herrera, vecino de Ciudad Real, hijo de Alonso de Herrera (m.). Contrata* a Bartolomé González y a *Pedro de Azuaga. 22-5: recibe de Bernardo de Grimaldo un préstamo de 72 ducados para su despacho (7.1506, 428r). 23-5: el maestre Juan Franco, vecino de Palos, se compromete a cargar en su nao San Juan las mercaderías que llevaba Herrera (Ibídem, 431r).

88. Fernando Martín de la Oliva, vecino de la Oliva. 17-1: con Juan Martín, vecino de Palos. 3 años. 8.000 mrs. (11.1506). 
89. Fernando Martínez, vecino de Sanlúcar la Mayor, hijo de Antonio Martínez. Véase Fernando Zambrano.

90. Fernando Martínez, Alonso Martínez y Gonzalo Martínez, vecinos de Torrejoncillo (ducado de Alba): 30 castellanos a Diego Sánchez Colchero por los tres (4. 1506, 3, 540v).

91. Fernando Martínez de Utrera, trabajador, vecino de Utrera. 14-1: con Juan Martín, vecino de Palos. 3 años. 8.000 mrs. (11.1506).

92. Fernando de Montoro, vecino de Montoro, hijo de Alonso Jiménez: 8 castellanos a Diego Rodríguez (4.1506, 2, 284v).

93. Fernando Moreno, criado de *Diego de Cáceres.

94. Fernando Moreno. Véase Simón Ruiz Romero.

95. Fernando de Porras, vecino de Sevilla (Santa María la Blanca), hijo del jurado Juan Gutiérrez de Porras. Contrata a *Juan Antón, a *Alonso Viejo, a *Francisco Fernández y a *Antón de Alcántara.

96. Fernando Sánchez, vecino de la Zarza de Alhanje (maestrazgo de Santiago). Véase Pedro Martínez.

97. Fernando Sánchez Durán, vecino de Alburquerque. Véase Gómez Nieto.

98. Fernando de Sepúlveda Cabeza, albañil, vecino de Granada en la puerta de Guadix, marido de Ana de Morales. 2-11: reconoce deber al mercader Álvaro de Plasencia, vecino de Sevilla (Santa María) ${ }^{45}, 12$ castellanos (en parte de pago dio dos ducados). Se embarca en la nao de Diego Sánchez Colchero $(10.1506,5 \mathrm{v})$.

99. Fernando Sobrino, gallego, vecino de La Coruña: 10 castellanos a Francisco López $(4.1506,2,558 \mathrm{v})$.

100. Fernando Vicente, vecino de Cáceres. 24-12: 3.600 mrs. a Fernando de Bonilla (15.1506, 2, 1.060r).

101. Fernando Zambrano y Fernando Martínez, hijo de Antonio Martínez, vecinos de Sanlúcar la Mayor: 16 castellanos a Diego Rodríguez por los dos $(4.1506,2,283 \mathrm{v})$

102. Francisca, hija de *Isabel Gómez.

103. Francisco, hermano del labrador *Francisco López.

104. Francisco, hijo del zurrador Rodrigo Salero, vecino de Sevilla (Santa María). 28-8: el padre da 7.000 mrs. a Juan de Medina por el flete de una yegua overa (y de "seys fanegas de çevada e una falda de paja e...una bota vasija para agua para la dicha yegua") y el pasaje de su hijo (4.1506, 3, 93r).

105. Francisco, herrador, vecino de Sanlúcar la Mayor, hijo de Alfonso Martínez, herrador: 8 castellanos a Diego Rodríguez $(4.1506,2,352 v)$.

45 Este Álvaro de Plasencia y Álvaro de Salinas cargaron sus mercancías en La Chacona, de la que era maestre Juan de Medina. El 2 de noviembre los dos mercaderes dieron poder para recogerlas a Juan Fernández de las Varas y a Pedro Núñez de Ávila, estantes en Santo Domingo, y asimismo para reclamar a Medina 10.000 mrs. por razón de los "gastos e mantenimientos" que ellos habían tenido que hacer $(10.1506,7 \mathrm{v}])$. 
106. Francisco Durán, vecino de las Garrovillas. Véase Diego Sánchez Ribero.

107. Francisco Fernández, vecino de la Hera de Hornachos (Orden de Santiago), hijo de Alonso Fernández. 25-1: con Fernando de Porras. 2 años. 5.000 mrs. $(5.1506,218 v)$.

108. Francisco Fernández de Ocaña, trabajador, vecino de Villanueva de los Infantes. 8-6: con Juan Pérez, vecino de Sevilla. 3 años. 5.000 mrs. (11.1506).

109. Francisco Fernández de Villalobos, vecino de Badajoz. Véase Lope García Garabato.

110. Francisco Gómez Biduero, vecino de Benalcázar: 12 pesos a Sancho de Salazar $(4.1506,3,478 \mathrm{r})$.

111. Francisco de Heredia, natural de Guadalcanal. 26-8: 9 castellanos a Francisco López (11.1506).

112. Francisco Jiménez, vecino de Sevilla. Contrata a *Juan Sánchez de Talavera.

113. Francisco López, labrador, vecino de Arjona, hijo de Antón Ruiz: 31 pesos a Sancho de Salazar por él, su hijo Juan y su hermano Francisco (4.1506, 3, $333 \mathrm{v})$.

114. Francisco López y Gonzalo Fernández de Utrera, vecinos de Badajoz: 20 castellanos a Diego Sánchez Colchero por los dos (4.1506, 3, 568r).

115. Francisco Montesino, natural de Carmona. 23-12: 8 castellanos a Fernando de Bonilla (15.1506, 2, 1.061r).

116. Francisco de Osuna, trabajador, hijo de Martín de Osuna (vecino de Écija). 7-4: con el mercader Pablo de Ávila, vecino de Madrid. 2 años. 4.500 mrs. "e en cada un año dos camisas d'estopa e un cosete e unos calçones e más los çapatos o alpargates que oviere menester" (10.1506, 12r).

117. Francisco Ruiz, trabajador, natural de Sahagún, criado de Francisco de Riberol. 15-6: con dos socios, el mercader Sancho López, estante en la Española, y el procurador Luis Fernández, vecino de Sevilla (Magdalena). 2 años. 8.000 mrs. Se embarca en la nave de Diego Rodríguez (10.1506, 16v).

118. Francisco Sánchez Moreno y Miguel González, vecinos de Fuentes (Orden de Santiago). 19-12: 13 pesos a Fernando de Bonilla por los dos (15.1506, 2, $1.020 \mathrm{v})$.

119. Francisco de Villalón, hijo del mercader Juan Cerón (vecino de Villalón). 186: con los mercaderes Diego de Cea y Fernando de Córdoba, estantes en la Española, y Juan de Cea, vecino de Sevilla (Salvador). 2 años. 2.600 mrs. Se embarca en la nave de Diego Rodríguez (10.1506, 24r).

120. Francisco de Zamora, boticario, vecino de Sevilla (Santa María). 14-10: el boticario genovés Jerónimo Barón le da poder para cobrar deudas suyas en Indias: “de *** de Medina, vezino d'esta dicha çibdad, estante en la isla Española, e de sus bienes e de quien con derecho deva dos mill e dozientos mrs. que me deve por una obligaçión que contra él tengo; e asimismo de Johan 
de Xerez, boticario, vezino d'esta dicha çibdad e de sus bienes todos los mrs. e medeçinas e debdas que me deve de la fazienda que yo, el dicho Gerónimo Barón, le di que vendiese en en la dicha isla” Española (4.1506, 4, 106r).

121. García Fernández Mendo, vecino de Arroyo del Puerco, hermano de *Alfonso González Mendo.

122. Gil García de Miranda, natural de Trujillo: 8 castellanos a Francisco López (4.1506, 3, 61r).

123. Ginés Martínez, vecino de la Mormenda: con Pedro de Uclés. 2 años. 4.000 mrs. $(4.1506,3,474 \mathrm{v})$.

124. Gómez Bernal, carpintero, vecino de Sevilla (San Marcos). 15-5: con Álvaro y Fernando de Briones. 2 años. 12.000 mrs. (15.1506, 1, 1.044v).

125. Gómez Nieto, Fernando Sánchez Durán y Bartolomé Rodríguez, vecinos de Alburquerque: 30 pesos a Diego Sánchez Colchero por los tres $(4.1506,3$, 536v).

126. Gonzalo, vecino de Sanlúcar la Mayor, hijo de Pedro Fernández Morejón. Véase Lucas Bejarano.

127. Gonzalo de Baena, ropero, vecino de Sevilla (Santa María). 11-10: a medias con Pedro de Arguijo, alguacil de Sevilla (San Bartolomé), envía a las Indias una "yegua castaña, calçada de todos quatro pies con una estrella en la frente", consignada a Juan López de Oquina, maestre del San Lorenzo; Baena habría de venderla en la Española para que los dos socios se repartieran las ganancias a partes iguales $(5.1506,392 \mathrm{v})$.

128. Gonzalo Boadira, hijo de Alonso Martínez Boadira. Véase Tomás del Río.

129. Gonzalo Cermeño, natural de Niebla: 9 castellanos a Diego Rodríguez $(4.1506,2,335 \mathrm{v})$.

130. Gonzalo de Corvera, vecino de Sevilla (Santiago) y también, según las escrituras, vecino de Santo Domingo (y antes, en 1504, de Baeza). Contrata a *Pedro Martínez de la Baquera y a *Juan Fraile, vecino de Carrión de los Condes. 22-9: reconoce deber a Diego de Escobar, vecino de La Vega, 300 ducados que le había prestado para despacho de las mercaderías que llevaba cargadas en la nao de Alonso Cota (15.1506, 2, 319r). 22-9: a su vez, Diego de Escobar dio poder a su sobrino Juan de Estrada, a Diego de Sanlúcar y a Cristóbal Vallés para cobrar ese dinero (15.1506, 2, 320v). El 14 de marzo de 1506, en Santo Domingo, Alonso Pérez Roldán, vecino de Santo Domingo, otorgó poder al doctor Gonzalo de León, a Juan Roldán y a Francisco Quixada, vecinos de Sevilla, para presentar una citatoria contra Corvera ante cualquier justicia; el doctor León otorga poder general en el dicho nombre a Diego López el 15 de mayo siguiente, en Sevilla $(15.1506,1,1.031 v)$.

131. Gonzalo Díaz, mercader, vecino de Lopera (Orden de Calatrava). 21-10: hace compañía con el mercader Juan de Baena, vecino de Sevilla (Magdalena), comprometiéndose a ir a Indias y a vender a los mejores precios las mercan- 
cías que Baena le enviase, bien entendido que, "sacado el prinçipal e costo de todo ello, que la terçia parte que en ello se ganare sea de ambos a dos e la partamos de por medio, e las otras dos partes dela dicha ganançia e el dicho prinçipal sea para la presona cuya fuere la mercadería", excepto que la ropa fuese de Baena; entonces Díaz la habría de vender sin obtener de ello ganancia alguna (3.1506).

132. Gonzalo Fernández, vecino de Sevilla. Contrata a *Juan Gutiérrez de Aranda.

133. Gonzalo Fernández, boticario, vecino de Sevilla (San Ildefonso), marido de Juana de Jerez. 24-9: hace compañía con el boticario sevillano Juan Bernal. Las "mercaderías, drogas y medicinas" que le entrega Bernal, apreciadas en 25.000 mrs., son cargadas en la nao Santa Catalina, de que era maestre Alonso Cota. Llegado a la Española, Fernández habría de poner "tienda de botiquería" y otras mercaderías e "arreo de tienda e paíla de morteros" hasta en cuantía de 15.300 mrs. Algunas condiciones son interesantes: "los mrs. que se fizieren de cada día en la dicha tienda, que se echen en un arca con dos llaves, e que la una tenga yo, el dicho Gonçalo Fernández, e la otra Luys de Córdova, mercader, estante en la dicha isla; e qu'el dicho Luys de Córdova pueda visitar la dicha tienda en lugar de vos, el dicho Johán Bernal; e que cada día se numeren los mrs. que se fizieren en la dicha tienda, e que no pueda malbaratar yo, el dicho Gonçalo Fernández, cosa alguna de la dicha tienda en ¿perdimiento? de la dicha conpañía sin liçençia del dicho Luys de Córdova; e que yo... tenga un libro e el dicho Luys de Córdova otro en vuestro nonbre, en el qual se asiente el reçibo y gasto de la dicha tienda; e que no aya el dicho Luys de Córdoba por lo susodicho salario ni interese ninguno en la dicha ropa...; e que sea obligado yo... a enbiar de los primeros mrs. que fiziere dineros a vos, el dicho Juan Bernal, para que me podades enbiar derogas $[s i c]$ e medeçinas a la dicha isla para proveer la dicha tienda, e que seáys obligado a me enbiar las dichas medeçinas e derogas al preçio que entre mí e vos las tenemos taçadas". Una vez que, pasados los dos años, Jerez vendiera el negocio y regresase a España, los socios se repartirían a medias pérdidas y ganancias $(4.1506,3,491 r)$.

134. Gonzalo Fernández de Utrera, vecino de Badajoz. Véase Francisco López.

135. Gonzalo Izquierdo, carpintero, vecino de Huévar, marido de Leonor Ruiz: 9 castellanos a Francisco López (4.1506, 2, 658v).

136. Gonzalo Jiménez, natural de Guadalcanal. Véase Juan Sánchez Calatrava.

137. Gonzalo Lorenzo, vecino de las Garrovillas. Véase Pedro Lorenzo.

138. Gonzalo Martínez, vecino de Torrejoncillo. Véase Fernando Martínez.

139. Gonzalo Ruiz. Véase Simón Ruiz Romero.

140. Gonzalo Suárez, escudero, vecino de Sevilla (San Julián). 2-6: reconoce deber a Diego Suárez, vecino de Sevilla (Santa María), 24 ducados que le había prestado para hacer su viaje a Santo Domingo (7.1506, 366r). 
141. Isabel Díaz de Heredia, vecino de Sevilla, mujer del cordonero *Juan Rodríguez.

142. Isabel Gómez, vecino de Sevilla (Magdalena), mujer del cuchillero Francisco Rodríguez, estante en la Española: 25 castellanos a Francisco López por ella y sus hijas Juana y Francisca (4.1506, 2, 742v).

143. Juan, hijo de *Francisco López.

144. Juan, hijo de *María de Ortega.

145. Juan, hijo del zapatero Fernando Vázquez (vecino de Aldea del Obispo [Ciudad Rodrigo]). 21-3: con los socios Bernardino de Isla y Pedro García, vecinos de Medellín. 2 años. 3.500 mrs. y "en cada un año dos camisas d'estopa e un par de calçones e un jubón de cañamazo e dos pares de alpargatas", más otros $1.000 \mathrm{mrs}$. que le debían (10.1506).

146. Juan de Alfaro, estante en Sevilla. 14-1: con Juan Martín, vecino de Palos. 3 años. 8.000 mrs. (11.1506).

147. Juan Alfonso, vecino de Mérida. Véase Juan Ramos.

148. Juan Antón, vecino de Usagre. 25-1: con Fernando de Porras, vecino de Sevilla. 2 años. 5.000 mrs. $(5.1506,216 r)$.

149. Juan Avana, natural de Asturias. 12-5: con los socios Luis Fernández, vecino de Sevilla (Santa María), y Sancho López, estante en Santo Domingo. 2 años. $12.000 \mathrm{mrs}$. en total (11.1506).

150. Juan Caldera, vecino de las Garrovillas. Véase Diego Sánchez Ribero.

151. Juan de Cárdenas, vecino de Sevilla (Santa María), marido de Teresa Gómez. Contrata a *Juana.

152. Juan Daza, vecino de Medellín. Junto con Pedro Daza contrata a *Pedro Martínez y a *Fernando Sánchez.

153. Juan Esteban, vecino de Badajoz, hijo de Gonzalo Vázquez: 10 castellanos a Francisco López $(4.1506,3,774 \mathrm{v})$.

154. Juan Fernández, vecino de Almendral. Véase Cristóbal Domínguez.

155. Juan Fernández de Valdepeñas, vecino de Valdepeñas. 8-6: con Juan Pérez, vecino de Sevilla. 3 años. 5.000 mrs. (11.1506).

156. Juan de Fregenal, trabajador. 17-1: con Juan Alemán (Juan en tachadura). 2 años. 5.500 mrs. (11.1506).

157. Juan Fraile, vecino de Carrión de los Condes. Véase Pedro Martínez de la Baquera.

158. Juan de Godoy, vecino de Sevilla (San Esteban), hijo de Catalina de Godoy y de Fernando Rodríguez (m.). 26-5: 9 castellanos a Diego Rodríguez, pagados a su sobrino, el cómitre Bartolomé Rodríguez (4.1506, 2, 314r).

159. Juan Gutiérrez de Aranda, natural de Aranda de Duero. 21-1: con Gonzalo Fernández, vecino de Sevilla. 1 años. 5.000 mrs. (3.1506).

160. Juan de Jerez, boticario, vecino de Sevilla (San Vicente), marido de Inés Guillén. 22-7: hace compañía con el boticario sevillano Juan Bernal, vecino 
de Sevilla en la colación de San Andrés (4.1506, 3, 9r): “oblígome que... porné tienda de las dichas mercaderías e las benderé a los mejores preçios que pudiere, e todo lo que vendiere lo asentaré en mi libro e lo daré e entregaré a Luis de Córdova..., para qu'el dicho Luys de Córdova vos lo envíe a esta çibdad; e que yo me mantenga de la dicha tienda, e que pueda tener un moço que vos, el dicho Juan Berenal, me dais, e qu'estaré en la dicha tienda dos años primeros siguientes... e que en fin de los dichos dos años venda todo lo que [res]tare en la dicha tienda e me benga a esta [çibd]ad; e que, venido, bos dé cuenta por mi libro e asimismo las cartas de pago del dinero que diere al dicho Luys de Cordova; e fecha cuenta entre nos de todo el pro e ganançia que Dios diere, aya yo, el dicho Juan de Xerez, la una terçia parte de la dicha ganançia; e que si yo adquiriere alguna cosa por mi trabajo e industria en la dicha isla, que sea obligado a lo meter en la dicha conpañía e vos dar cuenta d'ello":

161. Juan López, vecino de la Puebla del Maestre. Véase Alfonso Fernández.

162. Juan López, calero, vecino de Sevilla (Santa María), marido de Catalina Díaz. 20-5: con Álvaro y Fernando de Briones. 2 años. 5.500 mrs. (15.1506, 2, 15r).

163. Juan López de la Iglesia, tejedor de paños, vecino de Torre del Campo (Córdoba). Véase Simón Ruiz Romero.

164. Juan Maldonado, vecino de Cazalla de la Sierra, hijo de Pedro Fernández de Castillejo: 9 castellanos a Francisco López (4.1506, 2, 696r).

165. Juan Martín, vecino de Palos. Contrata a *Fernando Martín de la Oliva, a *Fernando Martínez de Utrera y a *Juan de Alfaro.

166. Juan Mill, vecino de Córdoba (Santiago). Contrata a *Sancho de Buenosvinos el Mozo.

167. Juan Molano (o tal vez molinero), vecino de las Garrovillas. Véase Pedro Lorenzo.

168. Juan de Morales, vecino de Villaverde (arzobispado de Sevilla). Véase Miguel de Ortega.

169. Juan Pago, zurrador, vecino de Jerez de la Frontera, hijo de Diego de Arcos. 10-1: con Lorenzo de Ahumada: 1 año, sin sueldo, pero pagándole Ahumada el pasaje $(4.1506,1,25 \mathrm{r})$.

170. Juan de la Parra, vecino de Montánchez: con Pedro de Uclés. 2 años (4.1506, $3,379 r$ ).

171. Juan Pérez, vecino de Cáceres. Véase Sebastián Moreno.

172. Juan Pérez, vecino de Sevilla (San Vicente). Contrata a *Diego de la Bastida, a *Francisco Fernández de Ocaña, a *Juan Hernández de Valdepeñas y a *Sebastián Alonso. 3-3: recibe del marinero Fernando de Morales 4.5000 mrs. que le debían tanto Morales como Juan de Sevilla, dándole poder a Morales para cobrar a Sevilla la mitad de esa suma (3.1506). 
173. Juan Ramos y Juan Alfonso, vecinos de Mérida: 24 pesos a Sancho de Salazar (4.1506, 3, 464v).

174. Juan Rodríguez, cordonero, vecino de Sevilla (Magdalena), y su mujer Isabel Díaz de Heredia. 21-10: antes de partir a las Indias dan testimonio ante escribano de que se han velado como marido y mujer por la Iglesia, siendo testigos los cordoneros Juan Rodríguez de Santa Cruz y Francisco Rodríguez. Se embarcan en la nao de Esteban de Guecho (3.1506).

175. Juan Rodríguez Berrueco, natural de Guadalcanal. Véase Juan Sánchez Calatrava.

176. Juan Ruiz, vecino de Arjona, marido de María Gómez: 12 pesos a Sancho de Salazar $(4.1506,3,327 \mathrm{v})$.

177. Juan Ruiz de Montalvo, cuñado de *Pedro Ruiz.

178. Juan Sánchez Calatrava, natural de Fregenal, y Juan Rodríguez Berrueco, Alfonso Rodríguez y Gonzalo Jiménez, vecinos de Guadalcanal: 36 castellanos a Diego Rodríguez por los cuatro (4.1506, 2, 443r).

179. Juan Sánchez Galindo, vecino de Tocina, hijo de Antón Sánchez. 5-9: con Francisco del Castillo, estante en la Española, y Alonso de la Barrera, para servir a Castillo en Indias. 2 años. 6.000 mrs. Dan fe de su identidad Alonso de Quesada, vecino de Sevilla (San Nicolás), y Juan López, vecino de Tocina (5.1506, 84r).

180. Juan Sánchez de Requena, albañil, vecino de Sevilla (Omnium Sanctorum), marido de Marina Núñez: 16.000 mrs. a Francisco López por sí y ocho personas más $(4.1506,2,728 r)$.

181. Juan Sánchez de Talavera, natural de Talavera, hijo de Alfonso Sánchez: con el mercader sevillano Francisco Jiménez (había de prestar servicios a Jiménez y al sobrino de éste, Diego López, o a quien López quisiere). 4 años. 5.000 mrs. (4.1506, 3, 142v).

182. Juan Serrano y Pedro del Guijo, vecinos de La Moraleja (tierra de la Orden de Alcántara): 16 castellanos a Francisco López por los dos (4.1506, 2, 644r).

183. Juan de la Torre, vecino de Córdoba, hijo de Miguel Ruiz Perdiguero. 12 -5: con Luis Fernández, vecino de Sevilla, y su socio Sancho López, estante en la Española. 2 años. 12.000 mrs. en total (11.1506).

184. Juana, hija de Pedro Mata. 16-3: con Juan de Cárdenas y su mujer Teresa Gómez, tanto en Castilla como en la Española. 4 años. 3.000 mrs., a pagar en Sevilla (4.1506, 1, 374r).

185. Juana, hija de *María de Ortega.

186. Juana, hija de *Isabel Gómez.

187. Leonor de Porras, vecina de Sevilla (Santa María), mujer de Juan de Mata, alguacil del arzobispado de Sevilla, estante en Santo Domingo. 27-5: 21.500 mrs. a Diego Rodríguez por sí y otras cuatro personas más. Lleva una tonelada de ropa, por la que paga $1.200 \mathrm{mrs}$. amén de $100 \mathrm{mrs}$. de averías; el maestre le presta 9.000 mrs. para su atavío (4.1506, 2, 312r). 
188. Lope García Garabato y Francisco Fernández de Villalobos, vecinos de Badajoz: 20 castellanos a Diego Sánchez Colchero por los dos (4.1506, 3, 567r).

189. Lorenzo de Ahumada, vecino de Sevilla (Santa María). Contrata a *Juan Pago. 3-1: estando a punto de zarpar, Lorenzo recibe un poder del mercader vizcaíno Martín de Xerondo para cobrar del serrador sevillano Esteban Núñez, estante en la Española, 3.000 mrs. que Núñez debía a Xerondo (4.1506, 1, 22v).

190. Lucas Bejarano, vecino de Sanlúcar la Mayor, hijo de Pedro Fernández Morejón, y Gonzalo, su hermano: 18 castellanos a Francisco López por los dos $(4.1506,2,713 \mathrm{r})$.

191. Luis Fernández, vecino de Sevilla (Santa María). Con Sancho López Contrata a *Juan de Avana, a *Juan de la Torre y a *Martín Fernández Pescador.

192. Luis Jiménez de Jaén y ***, vecinos de Jaén. 20-8: 40 castellanos a Francisco López por ellos y sus mujeres e hijos (4.1506, 5, 200r).

193. María, hija de Catalina de la Mora, vecina de Sevilla. Véase Catalina de la Mora.

194. María de Ortega, vecina de Sevilla (Santa María), mujer de Gaspar de Escobar, estante en la Española: 33 pesos a Sancho de Salazar por ella y sus hijos Juan y Juana (4.1506, 3, 335v).

195. Marina Bernal, mujer de Cristóbal Rodríguez Torres. Contrata a *Bartolomé de Carmona.

196. Martín Bogado, vecino de Bollullos de la Mitación, hijo de Fernando Bogado. 13-10 (corregido sobre 14): con Martín de Gamboa, "así en cavar e sacar oro como en todas las otras cosas que vos me dixerdes e mandardes". 2 años. 2.500 mrs. (5.1506, 120r).

197. Martín de Cabra, trabajador, vecino de Sanlúcar la Mayor, y Pedro García, su cuñado: 9 castellanos a Francisco López al parecer por los dos (4.1506, 2, $65 \mathrm{v})$.

198. Martín de Cáceres, tejedor de terciopelo, vecino de Sevilla (San Vicente). Contrata a *Alejo de Medina y al albañil *Benito Maldonado. 28-10: dándoselas de "escudero" hace compañía a medias con el también escudero Alonso de Ocaña, vecino de Sevilla en la colación de San Esteban, metiendo mercaderías por un valor total de 15.000 mrs., de los que presta la mitad (7.500 mrs) a Ocaña $(15.1506,2,666 v) .6-11$ : recibe poder del también tejedor de terciopelo Diego de Valdés, vecino de Sevilla (San Vicente) para cobrar 9.180 mrs. de Bárbola de Vargas (4.1506, 5, 268r; en esta escritura Cáceres es llamado otra vez "escudero"). 6-11: su suegra, la corredera Constanza García, vecino de Sevilla (San Vicente) le da otro poder para reclamar y cobrar en la Española las siguientes deudas: $9.180 \mathrm{mrs}$. al sombrerero Juan 
Ortiz, marido de Luisa de Vargas, de una obligación que ésta le había otorgado (la suma que, como hemos visto, reclamaba Valdés a su hermana de Luisa, Bárbola); 3.000 mrs. a la dicha Bárbola de Vargas, por 3.000 mrs. que Constanza había pagado por ella a Isabel Díaz, vecino de Sevilla; diez reales a Alfonso Carrillo y *** mrs. al escudero Gonzalo Suárez (4.1506, 5, 270r).

199. Martín Corvo, labrador, hijo de Bartolomé Corvo (vecino de Alcántara). 22-

10: Reconoció deber a Alonso de Cáceres, vecino de Sevilla (Santa María), 12 pesos de oro que le había dado para pagar su flete y comida a Luis Fernández de Alfaro (10.1506, 86r).

200. Martín de Gamboa, vecino de Sevilla (Santa María), marido de Juana de Astorga. Contrata a *Andrés Díaz y a *Martín Bogado. 26-8: da poder a Pedro de Arbolancha, vecino de Sevilla (Santa María), estante en la Española, para recibir de Antón García, vecino de Moguer, mastre de la nao Santa María, de la que era propietario Arbolancha, las mercancías que le había enviado en dicha nao (5.1506, 64r). 23-9: reconoce que debe a Juan de Valtierra 10 ducados que éste le había prestado $(5.1506,100 v)$.

201. Martín Fernández Pescador, vecino de Utrera. 13-5: con Luis Fernández, vecino de Sevilla, y su socio Sancho López, estante en la Española. 2 años. $16.000 \mathrm{mrs}$. en total (11.1506).

202. Martín Muñoz, trabajador, vecino de Montánchez. 15-9: con Pedro de Uclés. 2 años. 4.000 mrs. (4.1506, 3, 378r).

203. Martín Sánchez, vecino de Salamanca. Véase Alonso de Salamanca.

204. Martín Sánchez, carpintero, vecino de Sevilla (San Bartolomé). 16-5: con Álvaro y Fernando de Briones. 2 años. 7.500 mrs. (15.1506, 1, 1.064r).

205. Miguel González, vecino de Fuentes. Véase *Francisco Sánchez Moreno.

206. Miguel de Ortega y Juan de Morales, vecinos de Villaverde (arzobispado de Sevilla): 6.000 mrs. a Francisco López por los dos al parecer (4.1506, 3, 26v).

207. Pablo de Ávila, mercader, vecino de Madrid. Contrata a *Francisco de Osuna.

208. Pascual Maldonado, vecino de Sevilla (Magdalena), hijo de Pedro González Maldonado, natural de Chinchón, mayor de 18 años y menor de 25. 29-7: 7.000 mrs. a Francisco López (4.1506, 2, 764r). 4-8: reconoce deber a dicho maestre 12 ducados por mercaderías que había cargado en su nao, la San Pedro y San Pablo (4.1506, 5,126r).

209. Pedro, odrero, vecino de Sevilla (San Isidoro), hijo de Diego Manuel (m.), labrador. 3-6: con Francisco de Herrera, estante en la Española, y Juan de Palenzuela, vecino de Sevilla (San Isidoro), para servir al primero "en mi ofiçio de odrero e en todas las otras cosas que me dixerdes e mandardes". 2 años. 9.000 mrs., de los que recibió adelantados diez reales $(15.1506,1$, 923r). 
210. Pedro Alvarez, vecino de Alcántara. Véase Pedro de Medina.

211. Pedro de Azuaga, trabajador, hijo de Pedro Fernández del Rincón (vecino de Azuaga). 20-4: con el mercader Fernando de Herrera. 2 años. 4.000 mrs. "e más un cosete o jubón de cañamazo e unos calçones e dos camisas de estopa e dos pares de alpargatas" (10.1506, 29v).

212. Pedro Cobo. Véase Simón Ruiz Romero.

213. Pedro Chacón, vecino de Sevilla (Santa María). Contrata a *Diego de la Trinidad y a *Felipe Vázquez.

214. Pedro Daza, vecino de Medellín. Junto con Juan Daza contrata a *Pedro Martínez y a *Fernando Sánchez.

215. Pedro García, cuñado de *Martín de Cabra.

216. Pedro García, vecino de Almendral. Véase Cristóbal Domínguez.

217. Pedro García, vecino de Sanlúcar la Mayor (Santa María), hermano de Ruy Díaz de Vallejo.

218. Pedro García, vecino de Medellín. Junto con Bernardino de Isla contrata a *Juan, hijo de Fernando Vázquez.

219. Pedro de las Garrovillas, natural de las Garrovillas, hijo de Juan Alonso, herrero: 9 castellanos a Diego Rodríguez (4.1506, 2, 268r).

220. Pedro Gómez, vecino de Rota: 6 pesos a Sancho de Salazar (4.1506, 3, 533r).

221. Pedro del Guijo, vecino de La Moraleja (tierra de la Orden de Alcántara). Véase Juan Serrano.

222. Pedro Lorenzo, Bartolomé Martínez, Gonzalo Lorenzo Garrovillano y Juan Molano (¿o molinero?), vecinos de las Garrovillas: 39 castellanos a Francisco López por los cinco (4.1506, 2 f. 743v).

223. Pedro Martínez y Fernando Sánchez, vecinos de la Zarza de Alhanje (maestrazgo de Santiago). 22-9: con Pedro y Juan Daza, vecinos de Medellín. 2 años.16.000 mrs. Son testigos Diego Benítez y Juan Alonso, vecinos de la Zarza. Se embarcan en la nao San Juan que tenía por sobrenombre La Bachillera (21. 1506).

224. Pedro Martínez de la Baquera, vecino de Azuaga, y Juan Fraile, vecino de Carrión de los Condes. 15-10: con Gonzalo de Corvera, vecino de Santiago. 2 años. 8.000 mrs. (4.1506, 4, 145r).

225. Pedro Martínez Carvajeda (probablemente grafía errónea por Carballeda) y Alfonso Gómez de Pineda, vecinos de Villanueva del Ariscal: 18 castellanos a Francisco López por los dos $(4.1506,2,742 v)$.

226. Pedro Martínez Peña, tejedor de lienzos, vecino de Sanlúcar la Mayor, marido de Antonia Sánchez la Camacha: 5.000 mrs. a Francisco López (4.1506, 2, 762v).

227. Pedro de Medina, Pedro Álvarez, Pedro de Medina el Mozo y Alfonso Díaz Trujillano, vecinos de Alcántara: 50 castellanos a Diego Sánchez Colchero por los cuatro $(4.1506,3,520 \mathrm{r})$. 
228. Pedro de Medina el Mozo, vecino de Alcántara. Véase Pedro de Medina.

229. Pedro Muñoz, marido de Leonor Quintero, Juan Martín, hijo de Pedro Martín, y Alonso Fernández Carvallón, vecinos de Lucena (lugar del duque de Medina Sidonia). 6-3: 21 pesos a Juan Rodríguez Chocero por los tres (15.1506, 1, 490r).

230. Pedro de Ortigosa, natural de Almendralejo (Orden de Santiago), y Alonso Rodríguez, natural de Talavera de la Reina. 15-5: con Andrés Cataño y Diego de Alvarado. 3 años. 6.000 mrs. (15.1506, 1, 1046v).

231. Pedro Ruiz, labrador, vecino de la Fuente de Pero Abad (Córdoba): 24 pesos a Sancho de Salazar por él y por Juan Ruiz de Montalvo, su cuñado (4.1506, 3, 334v).

232. Pedro de Torredonjimeno, hijo de Diego Fernández, vecino de Torredonjimeno. Véase Bartolomé de Arjona.

233. Pedro de Uclés. Contrata a *Alfonso Sánchez, a *Diego Fernández del Coso (¿o Castillo?), a *Martín Muñoz, a *Juan de la Parra, a *Diego Lozano, a *Ginés Martínez, a *Diego Ruiz y a *Alfonso de Sevilla.

234. Pedro de Valera, albañil, vecino de Sevilla (San Lorenzo), marido de Isabel Sánchez: 10 castellanos a Diego Rodríguez, pagados a su sobrino, el cómitre Bartolomé Rodríguez (4.1506, 2, 290r).

235. Pedro de Villagarcía, hijo de Pedro Esteban Zazores, vecino de Villagarcía: 12 pesos a Sancho de Salazar $(4.1506,3,329 v)$.

236. Ruy Díaz, carpintero, vecino de Osuna, marido de Isabel de Vera. 27-5: con Andrés Cataño y Diego de Alvarado. 2 años. 8.000 mrs. (15.1506, 1, 886v).

237. Ruy Díaz de Vallejo y su hermano Pedro García, vecinos de Sanlúcar la Mayor (Santa María): 18 castellanos a Francisco López por los dos (4.1506, 2, 659v).

238. Ruy González y Diego Pérez, vecinos de Encinasola: 22 pesos a Luis Fernández de Alfaro por los dos (4.1506, 5, 197r). No pasó la escritura.

239. Sancho de Buenosvinos el Mozo, vecino de Córdoba (Santa María), hijo de Sancho de Buenosvinos. 12-5: con Juan Mill, vecino de Córdoba (Santiago). 2 años. 7.000 mrs. (4.1506, 2, 133r).

240. Sebastián Alonso, vecino de Zalamea del Arzobispo. 8-6: con Juan Pérez, vecino de Sevilla. 2 años. 12.000 mrs. (11.1506).

241. Sebastián Moreno, Juan Pérez y Andrés Martínez, vecinos de Cáceres: 27 castellanos a Francisco López por los tres (4.1506, 2, 660r).

242. Simón Ruiz Romero, labrador, y Juan López de la Iglesia, tejedor de paños, vecinos de la Torre del Campo (Córdoba), junto con Fernando Moreno, Gonzalo Ruiz y Pedro Cobo. 23-12: 48 castellanos (8 cada uno) a Fernando de Bonilla por los cinco (15.1506, 2, 1.059r).

243. Teresa Gómez, mujer de Juan de Cárdenas. Véase Juana, hija de Pedro Mata. 
244. Tomás del Río, vecino de Sevilla (San Lorenzo), hijo de Juan del Río (m.): 16 castellanos a Diego Rodríguez por él y por Gonzalo Boadira, hijo de Alonso Martínez Boadira (4.1506, 2, 307r).

245. $* * * 46$, tejedor de terciopelo, vecino de Sevilla: 9 castellanos a Francisco López (4.1506, 3, 11r26v).

246. ***, vecino de Jaén, con su mujer e hijos. Véase Luis Jiménez de Jaén.

247. Hijo *Antón García.

248-253. Hijos (seis) de *Antón Ronco.

253ss. Hijos de *Luis Jiménez de Jaén.

Hijos de $* * *$. Véase Luis Jiménez de Jaén.

Mujer de *Luis Jiménez de Jaén.

Mujer de ***. Véase Luis Jiménez de Jaén.

Cuatro personas que viajaron con *Leonor de Porras.

Ocho personas que viajaron con Juan Sánchez de Requena.

Mozo que fue con Bernardino de Tapia.

Recibido el 15 de mayo de 2006

Aceptado el 1 de agosto de 2006

46 Por el mal estado del documento original no acierto a leer el nombre en este y en el número siguiente. 